\title{
Validation of aggregate reference forecasts for passenger transport
}

Matts Andersson, K. Brundell-Freij and Jonas Eliasson

The self-archived postprint version of this journal article is available at Linköping University Institutional Repository (DiVA):

http://urn.kb.se/resolve?urn=urn:nbn:se:liu:diva-181285

N.B.: When citing this work, cite the original publication.

Andersson, M., Brundell-Freij, K., Eliasson, J., (2017), Validation of aggregate reference forecasts for passenger transport, Transportation Research Part A, 96, 101-118.

https://doi.org/10.1016/j.tra.2016.12.008

Original publication available at:

https://doi.org/10.1016/j.tra.2016.12.008

Copyright: Elsevier

http://www.elsevier.com/

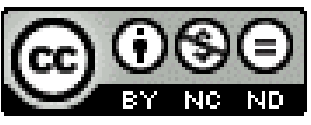




\title{
Validation of aggregate reference forecasts for passenger transport
}

\author{
Matts Andersson ${ }^{1,2}$, Karin Brundell-Freij ${ }^{1}$, Jonas Eliasson ${ }^{2}$ \\ ${ }^{1}$ WSP Analysis \& Strategy \\ ${ }^{2}$ Department for Transport Science, KTH Royal Institute of Technology
}

\begin{abstract}
We have compared Swedish national forecasts for passenger transport produced from 1975 to 2009 with the actual outcomes, and we found substantial differences between forecasts of passenger kilometers by mode and actual outcomes. In forecasts produced since the early 1990s, road and air traffic growth rates have generally been overpredicted. Aggregate railway growth has been fairly accurate, but commercial long-distance railway growth has been overpredicted, and the growth of subsidized intra-regional railway travel has been underpredicted (following vast unanticipated supply increases).

Focusing on car traffic forecasts, we show that a very large share of forecast errors can be explained by input variables turning out to be different than what was assumed in the forecasts. Even the original forecasts are much closer to actual outcomes than simple trendlines would have been, and once the input assumptions are corrected, the forecasts vastly outperform simple trendlines. The potential problems of using cross-sectional models for forecasting intertemporal changes thus seem to be limited. This tentative conclusion is also supported by the finding that elasticities from the cross-sectional models are consistent with those from a time-series model.
\end{abstract}

Keywords: Demand modeling, forecast, transport, accuracy, validation.

JEL Codes: R41, R42. 


\section{INTRODUCTION}

Transport forecasts play an important role in policy design, decision-making, and public debate. The question addressed in this paper is how accurate forecasts for passenger transport are and to what extent forecast errors can be explained by wrong assumptions about input variables. When discussing the validation of transport forecasts, it is useful to distinguish between reference forecasts, which predict transport volumes in a future year in a baseline scenario, and policy forecasts, which predict the effects of some policy by comparing "do-nothing" and "do-something" scenarios. Such "policies" can be any intervention in the transport system, including infrastructure investments, changes in prices or taxes, new regulations, and so on. In practice, a project forecast - such as the forecasted traffic volume on a planned road - is a mixture of the two in which a reference forecast gives the baseline traffic volumes in the do-nothing scenario (which is usually several years into the future), and a policy forecast predicts how traffic volumes will be changed by the new road. When analyzing forecast accuracy, however, it is useful to distinguish between the two for several reasons. In this paper, we analyze reference forecasts.

Reference forecasts tend to form our picture of the future and our intuitive view of what investments and policy measures we believe will be necessary. The importance of reference forecasts makes them debated. For example, in Norway they are often accused of underestimating road traffic volumes thus leading to underestimations of road investment benefits (Kjerkreit \& Odeck, 2009). In Sweden, voices in the debate have claimed the opposite (Ljungberg, 2014).

Sweden has a long tradition of producing (semi-)official national reference forecasts that form the baseline scenario for long-term national transport planning. This paper compares eight Swedish national forecasts for passenger traffic made between 1975 and 2009 with actual outcomes. Forecasts for car, rail and domestic air are analyzed. Bus travel is not analyzed since the statistics are to crude for this to be meaningful (only based on vehicle mileage). We also try to explain to what extent differences between forecasts and outcomes can be explained by wrong assumptions about input variables such as fuel prices and economic growth. Here, the focus is primarily on car traffic because assumptions about supply data (fares, service frequencies, etc.) for rail and domestic air are not documented well enough to make this possible.

The models used to produce the forecasts have varied over time, but they have all been variants of 4-step models producing detailed forecasts on network and origindestination levels, and they have all been estimated on cross-sectional data. The present paper focuses on how well the models have managed to predict aggregate numbers of total passenger kilometers by mode some time into the future (typically more than a decade). Using models estimated on cross-sectional data to predict future transport patterns implicitly assumes that cross-sectional relationships between variables and travel behavior are the same as the corresponding inter-temporal relationships. For example, if income levels increase over time, this is assumed to affect travel behavior in a way that corresponds with observed cross-sectional differences across income groups. Analogous assumptions are (implicitly) made for the effects of changes in car ownership, urbanization, and so on. A central, long-standing question in the transport forecasting literature is to what extent models estimated on cross-sectional data can be used to produce reference forecasts stretching decades into the future. One of the purposes of the present paper is to explore this issue. Focusing on aggregate reference forecasts (future passenger kilometers) produced by cross-sectional models might thus be seen as 
almost unfair as we focus precisely on what should be expected of the weakest point of such models. Still, the question is important because reference forecasts are most often produced by cross-sectional models. This practice is common due to the need for detailed forecasts for project analyses such as infrastructure investments. So far, it is only models based on cross-sectional data that are able to produce such detailed forecasts, and time series-based models are almost never able to produce network-level forecasts working instead only at an aggregate level.

The remaining paper is structured as follows. A literature review is given in section 2, data sources and the background to the forecasts we analyze are presented in section 3 , comparisons between forecasts and outcomes are presented in section 4, an analysis of the effect of input errors for car forecasts is presented in section 5, and the concluding remarks are given in section 6.

\section{LITERATURE}

When discussing forecast validation, a distinction between reference forecasts and policy forecasts needs to be made since conclusions regarding strengths and weaknesses might be very different. For example, if (hypothetically) reference forecasts tend to underestimate the growth of a particular mode, it does not necessarily follow that forecasts of the effects of an investment in that mode are underestimated. In particular, the distinction is important if the purposes are to improve forecasting models and to assess to what extent, under what circumstances, and for which applications models can be trusted. Often, however, this distinction is blurred; in particular, demand forecasts for any particular project are necessarily a mixture of the two, and only careful econometric work can disentangle errors in the reference forecast from errors in the policy forecast. Consequently, most forecast validation studies do not explicitly separate the two.

Most of the forecast validation literature deals with project-specific forecasts. There are, however, a few studies that have followed up on reference forecasts on a more or less aggregate level. SIKA (2005) compared Swedish forecasts made from 1975 to actual outcomes and concluding that forecasts had difficulties in catching trend breaks. Odeck (2013) followed up road traffic forecasts for Norway (both for different counties and the country as a whole) for the period 1996-2008 and found that the accuracy of the national forecasts was improved after a major model revision in 2001. National forecasts were unbiased after the model revision, but there were still variations among regions and time periods. The Department of Transport in the UK has carried out back-casting evaluations of their national transport model by using the model to make "predictions" for the years 1976 and 1991 and comparing these to national travel surveys from those years (Gunn, Miller, \& Burge, Peter, 2006). The predictions were for the number of trip-ends and for mode/destination choice, and they did not use the entire model to make transport forecasts. The model predicted the number of trips correctly for 1991, but overestimated it by $15 \%$ for 1976 . Trip-making in the London area was over-predicted by around $20 \%$ for both years (which was offset by under-predictions in the rest of the country). The authors found that the model had performed well in predicting back to 1991, but they concluded that the model had predicted little change in a situation in which there had been little change in the factors affecting mode and destination choice at an aggregate level.

Nicolaisen (2012) presented an ex-post evaluation of demand forecast accuracy for donothing alternatives based on an empirical study of 35 non-tolled road projects in Denmark and England. The results showed a tendency for systematic overestimation of travel demand in the do-nothing alternatives, on average by 7\%. This was in contrast to 
the systematic underestimation of travel demand observed in the "do-something" forecasts. The study also found that the variation in do-nothing forecast accuracy was much smaller than for do-something forecasts. Some econometrics were performed with regional economic growth, regional population growth, the year that the forecast was produced, and how many years into the future the forecast was attempting to predict travel demand, but no significant relationships were found. It is important to note that in contrast to this paper, Nicolaisen examined the actual value of the variables, not the difference between the assumed and the actual values.

Turning to the validation of project-specific forecasts, it seems fair to conclude from the literature that travel demand for new (untolled) road infrastructure projects tends to be underestimated (Flyvbjerg, Skamris Holm, \& Buhl, 2005; Nicolaisen, 2012; Nicolaisen \& Driscoll, 2014; Odeck \& Welde, 2011; Parthasarathi \& Levinson, 2010), while travel demand for rail infrastructure and toll-road projects tends to be overestimated (Bain, 2009; Button, Doh, Hardy, Yuan, \& Zhou, 2010; Flyvbjerg et al., 2005; Fouracre, Allport, \& Thomson, 1990; Nicolaisen, 2012; Odeck \& Welde, 2011; Pickrell, 1992).

A large part of the discussion in the literature about the reasons for the forecast errors is focused on political-economic and psychological factors. Flyvbjerg and associates (Flyvbjerg, 2009; Flyvbjerg, Holm, \& Buhl, 2002; Flyvbjerg et al., 2005) argue that the bias must be attributed to intentional misrepresentation by project developers. For example Flyvbjerg et al (2005) note that road forecasts "are substantially more balanced than rail forecasts, which indicates a higher degree of fair play in road traffic forecasting" [our emphasis]. However, Osland and Strand (2010) found no general support for the theory of strategic misrepresentation and argued that there are other mechanisms at work that could better help to explain the forecast inaccuracies. Eliasson and Fosgerau (2013) showed that bias might be due to selection bias without there being any bias at all in predictions ex ante, and that such a bias is bound to arise whenever ex ante predictions are related to the decisions on whether to implement projects. The analysis in this article is a complement rather than a substitute to the literature that discusses the causes for why forecasting errors occur. Only discussing psychological factors does not explain how errors were introduced into the forecasting process, and, conversely, our "technical" analysis does not provide the full explanation on why input errors were made.

The literature mentioned above concerns ex post evaluations, but there is also an extensive literature on a priori uncertainty due to input assumptions. The review of De Jong et al (2007) suggested that most such studies are based on various kinds of systematic sensitivity tests of models.

\section{DATA SOURCES AND FORECASTING MODELS}

Over the years, different public agencies have been responsible for producing the official national transport reference forecasts. We obtained the forecasted passenger volumes from the original forecast reports, and to the fullest extent possible we also obtained assumptions about input variables (GDP, fuel price, etc.) from the original forecast reports. Unfortunately, not all reports document input assumptions, and sometimes they do it in a way that makes it impossible to compare input assumptions with official statistics (for example, defining different kinds of railway traffic in a way that does not coincide with official statistics). This is an unfortunate practice not just for the purposes of forecast validation, it would be much easier to update forecasts that are just a few years old to a new baseline situation or to new scenario assumptions. 
The forecasts in our analysis were produced between 1975 and 2015 using different approaches reflecting four decades of development regarding state-of-practice and state-of-the-art for transport forecasting methodology. For the two oldest forecasts from 1975 and 1980, the detailed methodology was not presented in the published documents. A general description of the method from 1975 (Kommunikationsdepartementet, 1975) indicates that the approach was aggregate and partly judgmental ("no mathematical model") and based on "general assumptions", though acknowledging the competition between modes. In 1980, aggregate travel was forecasted for different trip purposes separately based on judgments and assumptions regarding the development of the most important determinants. In a second step, total travel volumes per purpose were split into modes based on a "combination of various contributing factors" that were not explicitly presented (Transportrådet, 1980).

The 1990 forecast represents the first generation of the methodology that subsequently became standard, including a comprehensive four-step approach based on nested logit models. In this first attempt, the sub-model for trip generation was not yet integrated in the nested structure, and model parameters for some trip types were transferred - or rescaled - from models estimated elsewhere (Transportrådet, 1991). The forecasts produced in 1992 returned to a more aggregate approach in which, for example, total car mileage was based on predictions of (i) total car ownership, and (ii) kilometers driven per car, with economic growth and petrol prices being central explanatory variables (Swedish Road and Transport Research Institute (VTI), 1992). After that, the 1996 forecasts again applied a nested structure similar to the one used in 1990, but with some regional differentiation with respect to parameters for intra-regional trips (Widlert, Swahn, Östlund, \& Algers, 1995). From 1999 onwards, the National Transport Model (Sampers) has been applied for the studied forecasts. In Sampers, demand is predicted in integrated nested structures (including trip generation) that differentiate between trip purposes and between intra-regional and inter-regional trips (Beser \& Algers, 2002).

Data on passenger kilometers by car are obtained by applying constant ridership to official statistics regarding vehicle kilometers travelled (VKT) for cars. VKT statistics are obtained from the Swedish Transport Analysis authority (Trafikanalys). From 1999, VKT statistics are based on data from annual vehicle inspections where odometer readings are recorded, which means that passenger traffic and goods/distributional traffic are separated by vehicle type. A drawback is that VKT by Swedish vehicles abroad are included, while VKT by foreign vehicles in Sweden are excluded. Before 1999, VKT statistics were based on traffic measurements. These have the benefit that they measure actual traffic in Sweden, but a disadvantage is that different types of road traffic are hard to separate. Another disadvantage is the sampling error because only a subset of roads can be measured (see Edwards et al (1999) for discussions on earlier measurements and SIKA (2004) for a thorough discussion of both measures). Data for railway traffic are also obtained from the Swedish Transport Analysis authority. A difficulty when evaluating forecasts for public transport modes is to make sure that the forecasts and the statistics include the same types of traffic, for example, separating regional travel from longdistance travel.

Our efforts to obtain documentation of past forecasts, along with statistics for actual outcomes of transport and input variables, have led us to the conclusion that assumptions need to be presented much more clearly and in a way that is comparable with official statistics. We also conclude that developments between the base year and the year the forecast is released need to be accounted for. Although it is somewhat 
complicated to choose the exact method (straightforward conversion, adjusting for the phase in the business cycle, etc.), it is clear that this should be done.

\section{COMPARISON BETWEEN FORECASTS AND OUTCOMES}

\subsection{Changes in Swedish passenger transport 1950-2013}

The general development of kilometers travelled in Sweden is shown in figures 1-3. Car traffic is excluded in Figure 2 to make changes in the other modes easier to see. (Estimates of passenger km by Walking, Cycling and Mopeds are included in official statistics, and shown in the figures accordingly. The estimates are however for many reasons much more uncertain than for other modes, and we will therefore neither discuss the development of these modes, nor analyze the differences to the corresponding forecasted volumes further in the paper).

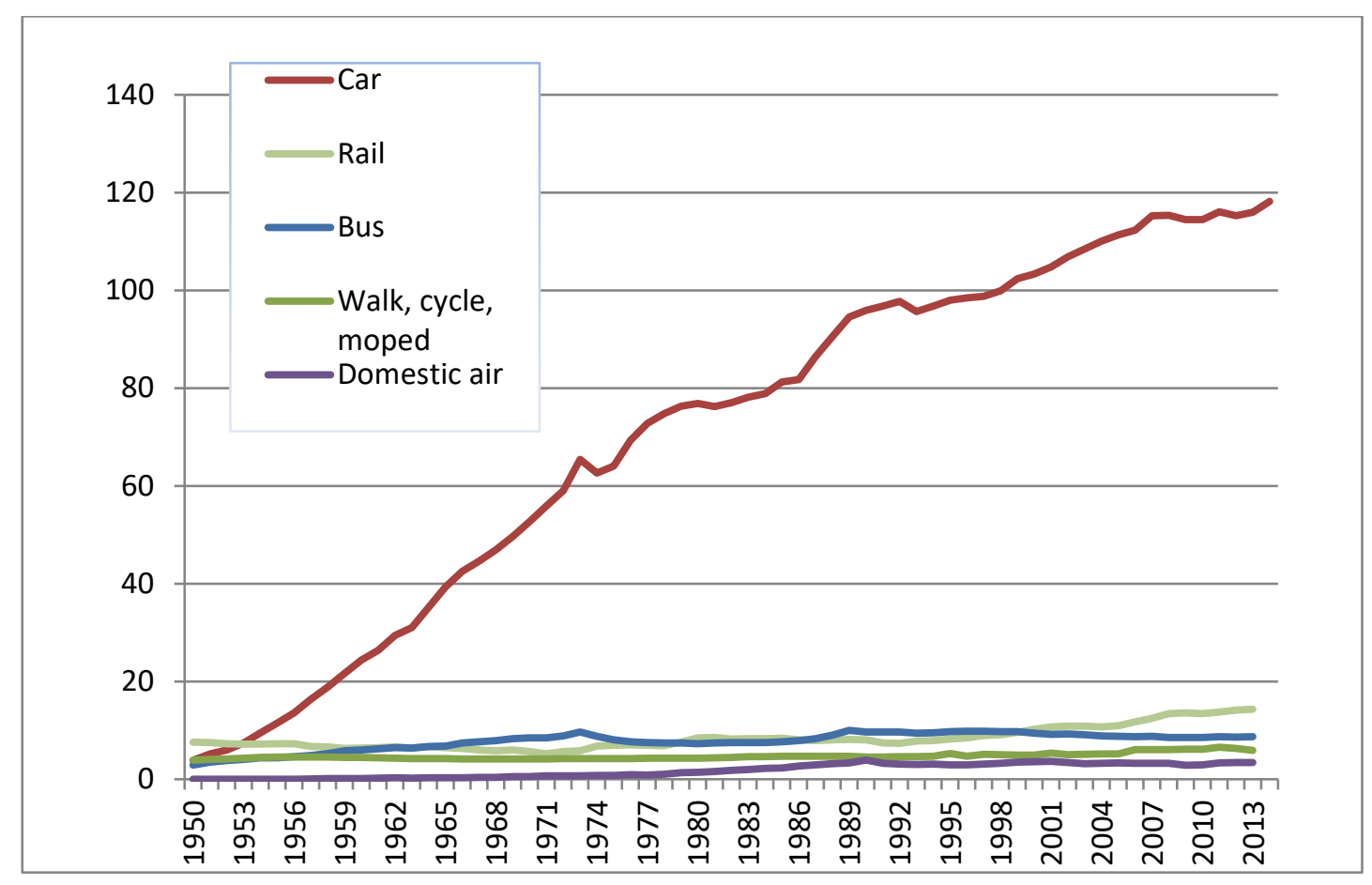

Figure 1. Total passenger kilometers per mode (billions per year). 


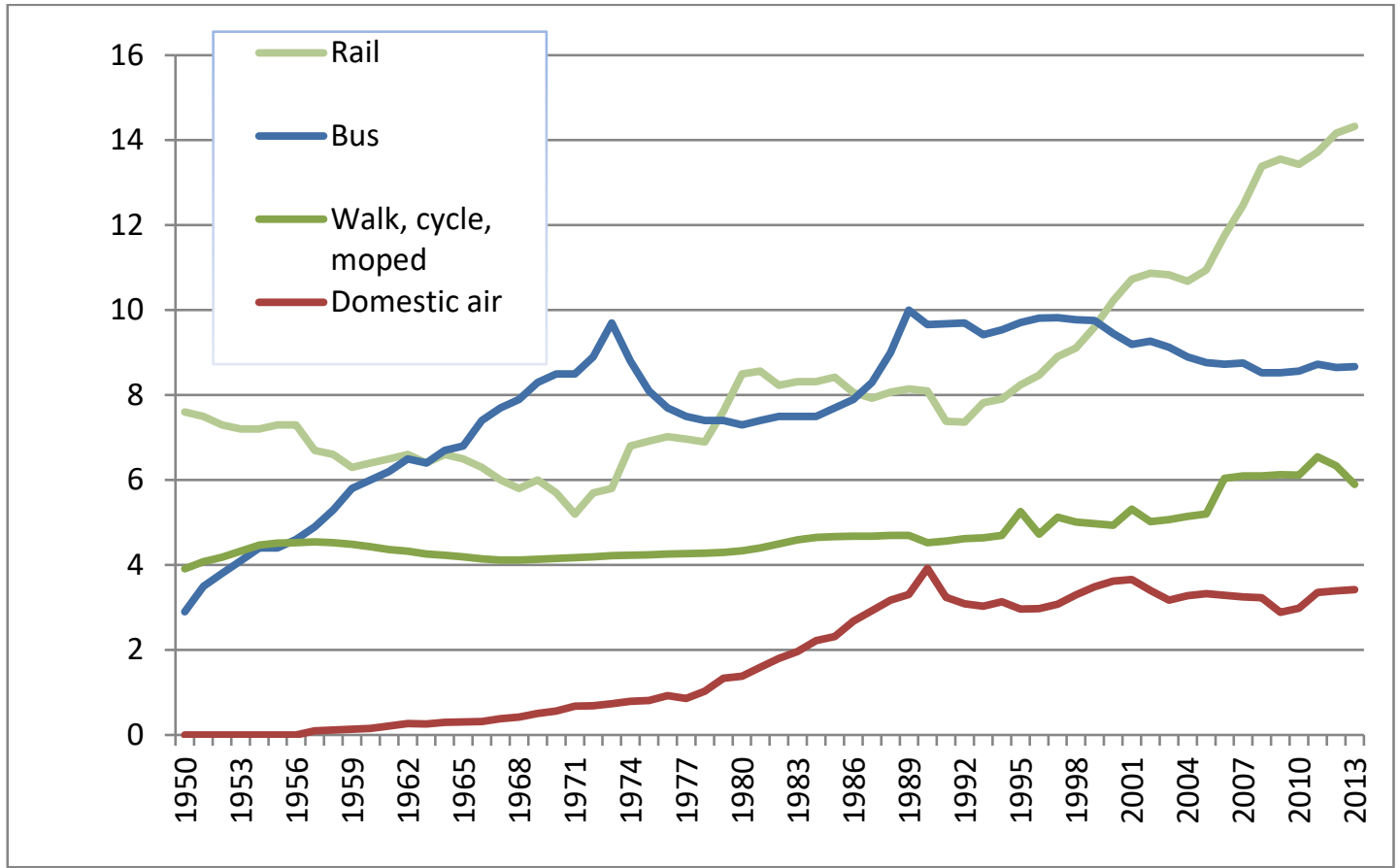

Figure 2. Total passenger kilometers per mode, excluding cars (billions per year).

Figure 1 shows that the car has been the dominant mode ever since its explosive growth during the 1950s and 1960s. The growth of car traffic has slowed down since then, and since 1990 car traffic has grown on average by $1 \%$ per year. Bus travel increased rapidly until 1970, then went down and up again in the 1970-1990 period, and has declined slightly since then. Domestic air travel increased explosively up to 1990, but then stopped growing and has remained essentially constant ever since.

In Sweden, statistics differentiate between commercial passenger traffic on longer distances (interregional henceforth), and train traffic for commuting and other daily travel (regional henceforth). Regarding interregional traffic, the most part of the traffic is operated by the state-owned company SJ. During the last few years, however, other operators have been allowed to compete with SJ for commercial passenger railway traffic. Regional train traffic is tax subsidized, run by regional public transport agencies, and forms an integrated part of regional public transport systems which includes also bus traffic. Local and regional public transport is typically subsidized by around $50 \%$. Before 1980, transport statistics did not distinguish between the two types of railway traffic.

Figure 3 shows all forms of railway traffic, including the metro (only in Stockholm) and trams (for which statistics are only available from 1997). Interregional railway traffic has grown at a considerable pace since deregulation of the industry in 1998, and yearly growth has been on average around 1.5\% compared to around $1 \%$ for car traffic. However, the rapid growth in total railway travel is mainly due to the growth in regional train travel, which has more than doubled in the last two decades. 


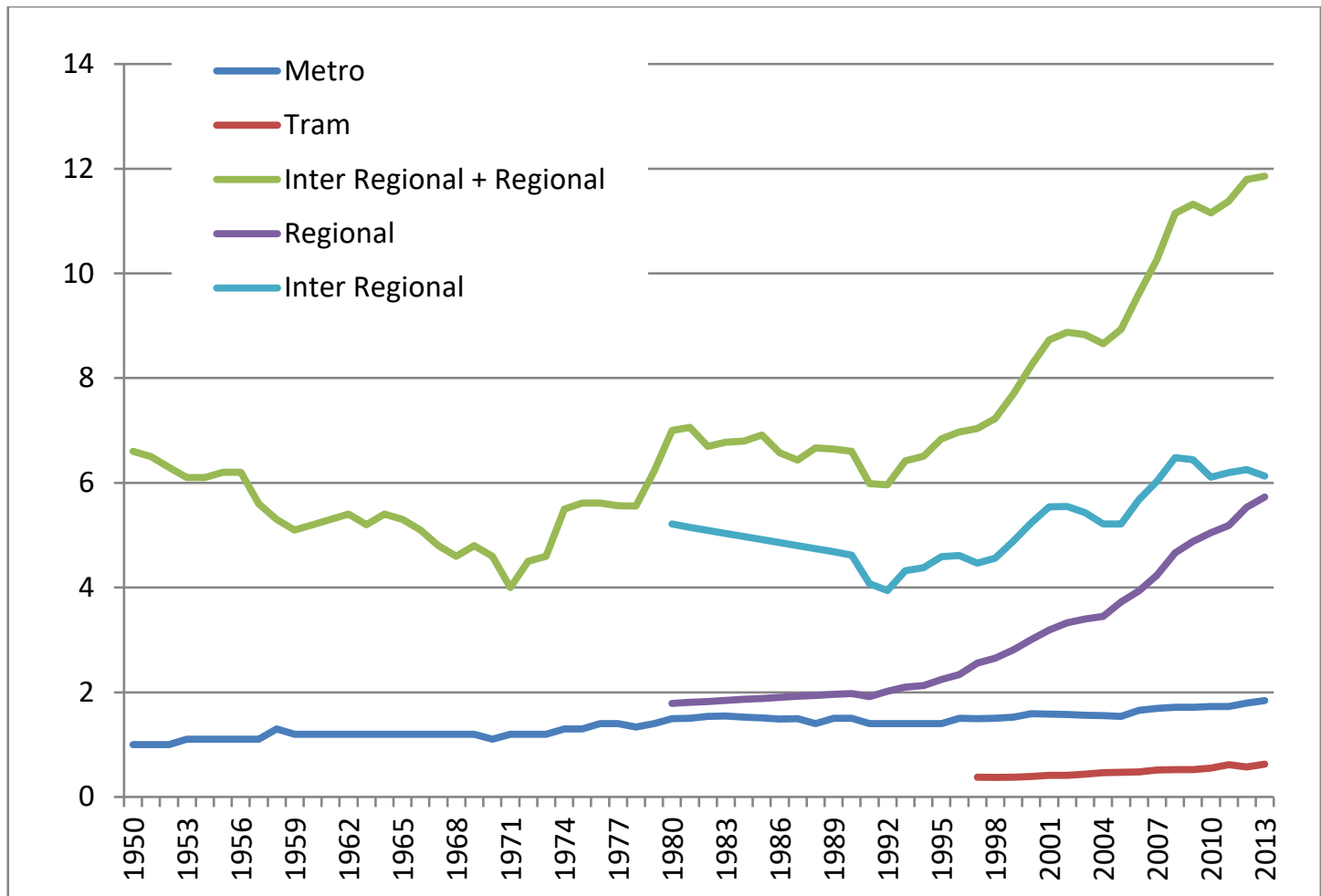

Figure 3. Total passenger kilometers for different types of railway traffic (billions).

\subsection{Forecasts for car traffic}

Table summarizes national forecasts and actual outcomes for car traffic (passenger kilometers) during the period 1975-2015. All forecasts in the table were "official" in that they were published by the national authority who at the time was responsible for making official long term transport forecasts to support the national transport planning process (responsibilities and organization has changed over time). An overview of the forecasting approaches and models, and how these developed over time, was presented in chapter 3. For recent forecast, for which the forecast year is still in the future, forecasted traffic growth has been interpolated to 2013, which is the last year for which statistics are available. In those rows, the "forecast year" is noted as 2013 and the real forecast year is noted within parentheses. On some occasions several scenarios with the same horizon were used, with different input assumptions (sensitivity analysis). For those cases, a very coarse description of the differences between scenario assumptions is given in the table. 


\begin{tabular}{|l|c|c|c|c|}
\hline Forecaster, year, scenario & $\begin{array}{c}\text { Start } \\
\text { year }\end{array}$ & $\begin{array}{c}\text { Forecast } \\
\text { year }\end{array}$ & $\begin{array}{c}\text { Forecast traffic } \\
\text { growth }\end{array}$ & $\begin{array}{c}\text { Actual } \\
\text { growth }\end{array}$ \\
\hline Dept of Transport, 1975, (high) & 1973 & 1980 & $\mathbf{1 7 \%}$ & $17 \%$ \\
\hline Dept of Transport, 1975, (high) & 1973 & 1990 & $\mathbf{3 5 \%}$ & $47 \%$ \\
\hline Dept of Transport, 1975, (low) & 1973 & 1980 & $\mathbf{9 \%}$ & $17 \%$ \\
\hline Dept of Transport, 1975, (low) & 1973 & 1990 & $\mathbf{2 0 \%}$ & $47 \%$ \\
\hline TPR, 1980 & 1980 & 1990 & $\mathbf{5 \%}$ & $25 \%$ \\
\hline TPR, 1990 & 1990 & 2000 & $\mathbf{2 0 \%}$ & $8 \%$ \\
\hline TPR, 1990 & 1990 & 2010 & $\mathbf{3 1 \%}$ & $19 \%$ \\
\hline TPR, 1990 & 1990 & $2013(2020)$ & $\mathbf{3 5 \%}$ & $21 \%$ \\
\hline VTI, 1992 & 1991 & 2005 & $\mathbf{2 6 \%}$ & $15 \%$ \\
\hline VTI, 1992 & 1991 & $2013(2020)$ & $\mathbf{4 1 \%}$ & $20 \%$ \\
\hline Samplan, 1996 & 1993 & 2010 & $\mathbf{3 0 \%}$ & $20 \%$ \\
\hline Samplan, 1999 & 1997 & 2010 & $\mathbf{2 0 \%}$ & $16 \%$ \\
\hline SIKA, 2005, (climate tax) & 2001 & $2013(2020)$ & $\mathbf{1 8 \%}$ & $11 \%$ \\
\hline SIKA, 2005, (current policy) & 2001 & $2013(2020)$ & $\mathbf{1 9 \%}$ & $11 \%$ \\
\hline Trp Adm, 2009, (climate package) & 2006 & $2013(2020)$ & $\mathbf{6 \%}$ & $3 \%$ \\
\hline Trp Adm, 2009, (no climate package) & 2006 & $2013(2020)$ & $\mathbf{1 2 \%}$ & $3 \%$ \\
\hline Trp Adm, 2012 & 2010 & $2013(2030)$ & $\mathbf{5 \%}$ & $1 \%$ \\
\hline Trp Adm, 2015 & 2010 & $2013(2030)$ & $\mathbf{4 \%}$ & $1 \%$ \\
\hline Table Car traffic & & & \\
\hline
\end{tabular}

Table 1. Car traffic (kilometers): forecasts and outcomes.

Figure 4 below summarizes most of the forecasts in Table 3 in a more illustrative way. The thick black line is actual car traffic, while the colored straight lines are forecasts ${ }^{1}$. Clearly, all forecasts since 1990 have overpredicted car traffic growth. The first forecast (Department of Transport, 1975) is approximately in line with the actual development. The second (TPR (Transport Council), 1980) misses the trend break in the mid 1980s and undershoots. No passenger traffic forecasts were carried out during the 1980s, the TPR reports from 1982, 1985, and 1986 only focused on model development.

\footnotetext{
${ }^{1}$ To make the diagram clearer a few sensitivity analysis are omitted and traffic volumes in the base years are assumed to be equal to actual levels. There are discrepancies between traffic volumes in the forecast reports and traffic statistics, but since our focus is the forecasted change we assumed it to be equal.
} 


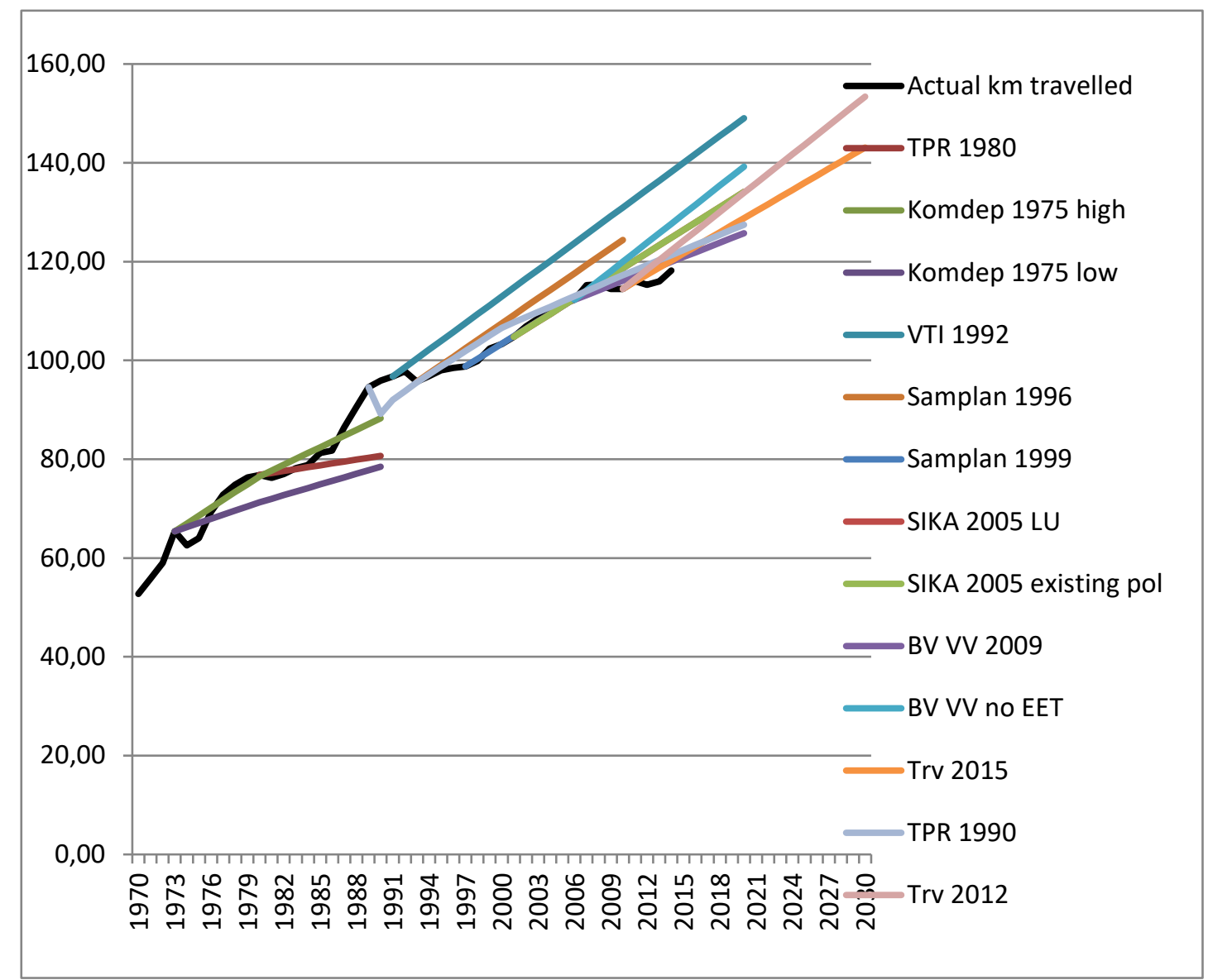

Figure 4. Car traffic (billion kilometers per year): forecasts and actual outcome.

Figure 5 compares forecast traffic growth per year with actual traffic growth. The diamonds above the dashed red line come from the 1975 and 1980 forecasts. All forecasts from 1990 and onward are below the line. Traffic growth has been overpredicted by a factor of 2 on average, whereas predicted growth factors have clustered around $1.5 \%$ and actual growth factors have clustered around $0.7-0.8 \%$. There is no apparent time trend in the forecasts, and the overpredictions have the same magnitude for all forecasts. It is, of course, too early to evaluate the latest available forecasts (from 2012 and 2015), but it is interesting to note that these forecasts imply about the same traffic growth as most forecasts made since 1990. 


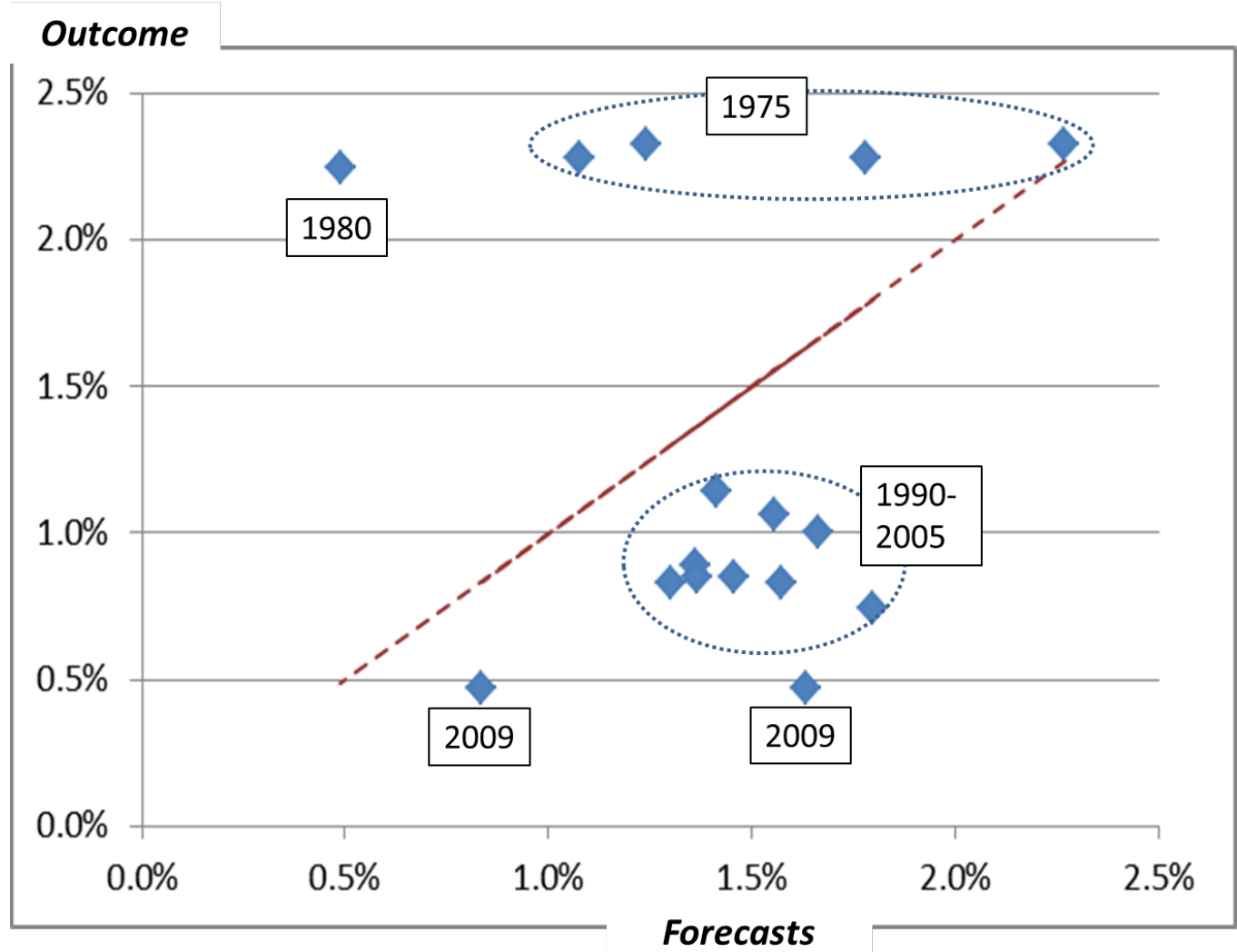

Figure 5. Traffic growth per year - forecasts (x-axis) and outcomes (y-axis). Numbers in boxes show the year the forecasts were made.

In chapter 5, we explore to what extent the overpredictions can be explained by errors in assumptions about input variables.

\subsection{Forecasts for railway travel}

Table 2 summarizes national forecasts and outcomes for railway traffic (passenger kilometers) during the period 1975-2015. Just as before, traffic growth has been interpolated to the year 2013 when the forecast years are still in the future. In such rows the "forecast year" is noted as 2013, and the real forecast year is noted within parentheses. There were fewer rail passenger forecasts that could be followed up compared to car forecasts: the VTI (1992) report does not present forecasts for rail or public transport, and the TPR (1990) and SIKA (2005) forecast reports do not separate between rail and bus. 


\begin{tabular}{|l|c|c|c|c|}
\hline Forecaster, year, scenario & $\begin{array}{c}\text { Start } \\
\text { year }\end{array}$ & $\begin{array}{c}\text { Forecast } \\
\text { year }\end{array}$ & $\begin{array}{c}\text { Forecast traffic } \\
\text { growth }\end{array}$ & $\begin{array}{c}\text { Actual } \\
\text { growth }\end{array}$ \\
\hline Dept of Transport, 1975, high & 1973 & 1980 & $6 \%$ & $46 \%$ \\
\hline Dept of Transport, 1975, high & 1973 & 1990 & $6 \%$ & $40 \%$ \\
\hline Dept of Transport, 1975, low & 1973 & 1980 & $6 \%$ & $46 \%$ \\
\hline Dept of Transport, 1975, low & 1973 & 1990 & $38 \%$ & $40 \%$ \\
\hline TPR, 1980 & 1980 & 1990 & $21 \%$ & $-5 \%$ \\
\hline Samplan, 1996 & 1993 & 2010 & $59 \%$ & $72 \%$ \\
\hline Samplan, 1999 & 1997 & 2010 & $31 \%$ & $51 \%$ \\
\hline Trp Adm, 2009, climate package & 2006 & $2013(2020)$ & $19 \%$ & $22 \%$ \\
\hline Trp Adm, 2009, no climate package & 2006 & $2013(2020)$ & $17 \%$ & $22 \%$ \\
\hline Trp Adm, 2012 & 2010 & $2013(2030)$ & $4 \%$ & $7 \%$ \\
\hline Trp Adm, 2015 & 2010 & $2013(2030)$ & $8 \%$ & $7 \%$ \\
\hline
\end{tabular}

Table 2. Railway passenger traffic (kilometers): forecasts and outcomes. Note: Interregional and regional trains are combined.

Figure 6 presents forecasts and outcomes in a more illustrative way. The thick black line is actual railway traffic, while the colored straight lines are forecasts.

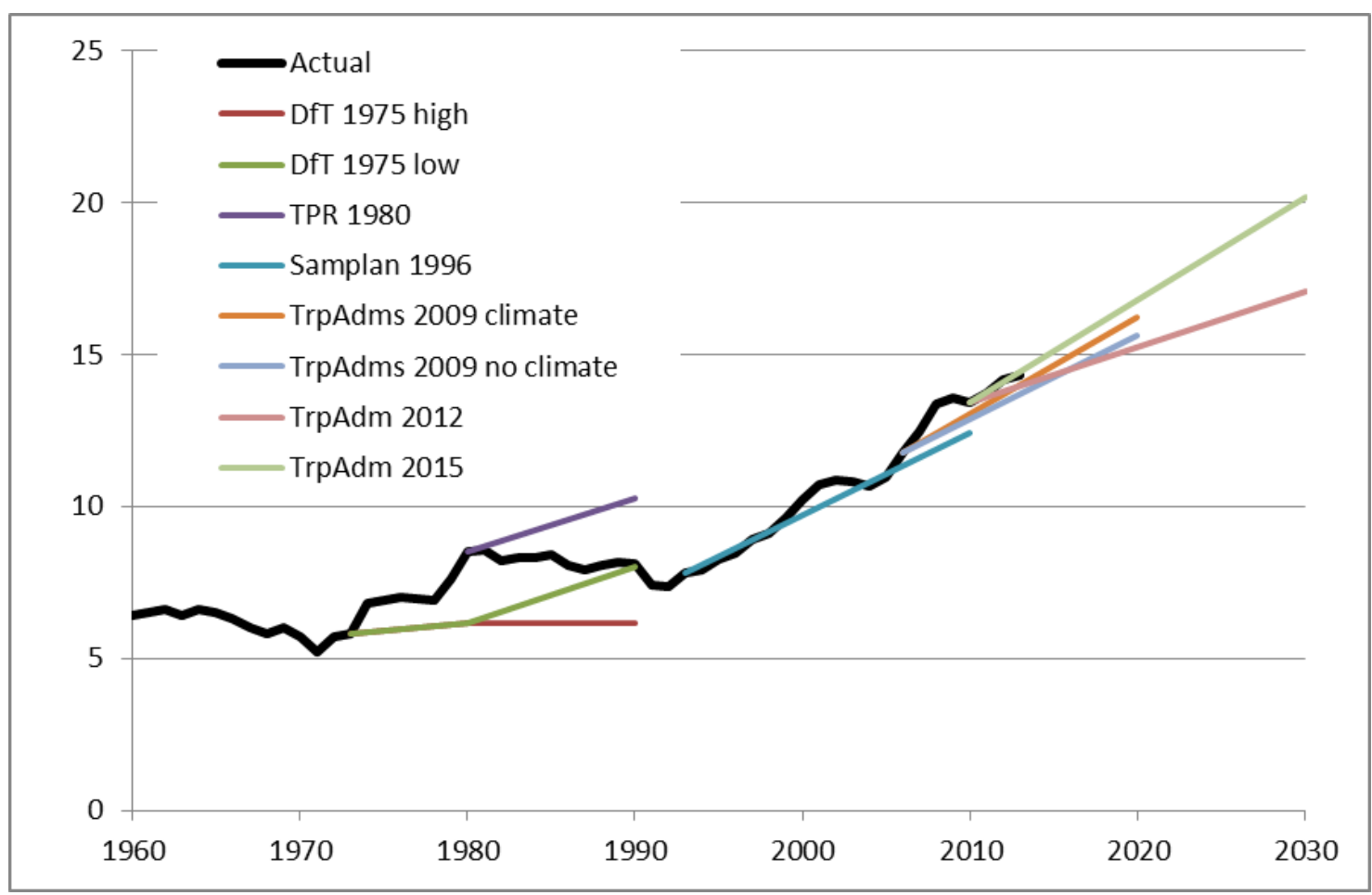

Figure 6. Total railway passenger kilometers (billions): forecasts and outcome.

Forecasts made during the 1970s and 1980s were mostly off target, but this is not surprising because regulations and organizations changed often and extensively during these years, and this had a strong influence on prices and supply.

Since 1990, the forecasts seem to have coincided reasonably well with the actual outcome. However, this seems to be at least partly due to luck - interregional passenger travel has grown slower than the forecasts, while regional train travel has grown much faster, and the two errors cancel each other out. Unfortunately, it is difficult to make detailed comparisons because most forecast reports do not document forecasts for interregional and regional train travel separately. Although several reports note that most of the predicted growth in railway travel is supposed to come from interregional 
train travel, they do not mention actual figures (or, more precisely, they do not provide enough detail to enable comparisons with outcomes). There are some exceptions, however. The Samplan 1999 forecast predicted that interregional railway travel would increase by $41 \%$ in the period 1997-2010 (the actual outcome was 37\%), which implies that regional train travel was predicted to increase by $14 \%$ (the actual outcome was 97\%). The SIKA 2005 forecast reported that interregional train travel was predicted to increase by $23 \%$ in 2013 (interpolated from the forecast to 2020), but the actual outcome was $11 \%$.

The most important factor for the increase in travel with regional train traffic is most likely the increase in supply. Supply measured as train vehicle-kilometers (seatkilometers are not available) more than doubled in the period 1990-2013. This increase in supply is not likely to have been demand driven (although population and GDP/capita have gone up); instead, it is more likely to have been driven by political decisions. Some of the most important of these are the formation of a jointly owned wagon company (Transitio), a state subvention of $50 \%$ of the cost of new trains (proposition 2001/02:20), and the fact that regional transport authorities were allowed to compete on the interregional market. This means that trains that are bought and operated with tax subsidies (roughly 50\%, this varies between regions) compete with non-subsidized trains. A contradicting supply trend is that fares for local public transport increased by $85 \%$ in real terms in 1985-2013, while fares for commercial interregional traffic have been roughly constant (own calculations based on SLTF statistics and SJ annual reports).

Whether the increase in public transport railway supply has been included in the forecasts is hard to say because the forecasts usually only mention assumptions made about single investments, not total vehicle kilometers. Our best guess is that this increase has not been included and that this is the main explanation for the underestimation of regional train travel. On the other hand, all forecasts assumed constant fares, but the fares for local public transport increased by 85\% between 1985 and 2013).

\subsection{Air travel forecasts}

Table 3 and Figure 7 summarize forecasts and actual outcomes for domestic air passenger travel.

\begin{tabular}{|l|c|c|c|c|}
\hline Forecaster, year, scenario & $\begin{array}{c}\text { Start } \\
\text { year }\end{array}$ & $\begin{array}{c}\text { Forecast } \\
\text { year }\end{array}$ & $\begin{array}{c}\text { Forecast traffic } \\
\text { growth }\end{array}$ & $\begin{array}{c}\text { Actual } \\
\text { growth }\end{array}$ \\
\hline Dept of Transport, 1975, high & 1973 & 1980 & $75 \%$ & $89 \%$ \\
\hline Dept of Transport, 1975, high & 1973 & 1990 & $213 \%$ & $436 \%$ \\
\hline Dept of Transport, 1975, low & 1973 & 1980 & $75 \%$ & $89 \%$ \\
\hline Dept of Transport, 1975, low & 1973 & 1990 & $138 \%$ & $436 \%$ \\
\hline TPR, 1980 & 1980 & 1990 & $40 \%$ & $183 \%$ \\
\hline TPR, 1990 & 1990 & 2000 & $57 \%$ & $-8 \%$ \\
\hline Samplan, 1996 & 1993 & 2010 & $36 \%$ & $-2 \%$ \\
\hline Samplan, 1999 & 1997 & 2010 & $17 \%$ & $-3 \%$ \\
\hline SIKA, 2005, indicated policy & 2001 & 2020 & $39 \%$ & $-19 \%$ \\
\hline Trp Adm, 2015 & 2010 & $2013(2030)$ & $3 \%$ & $15 \%$ \\
\hline
\end{tabular}

Table 3. Air passenger travel (kilometers): forecasts and outcomes. 


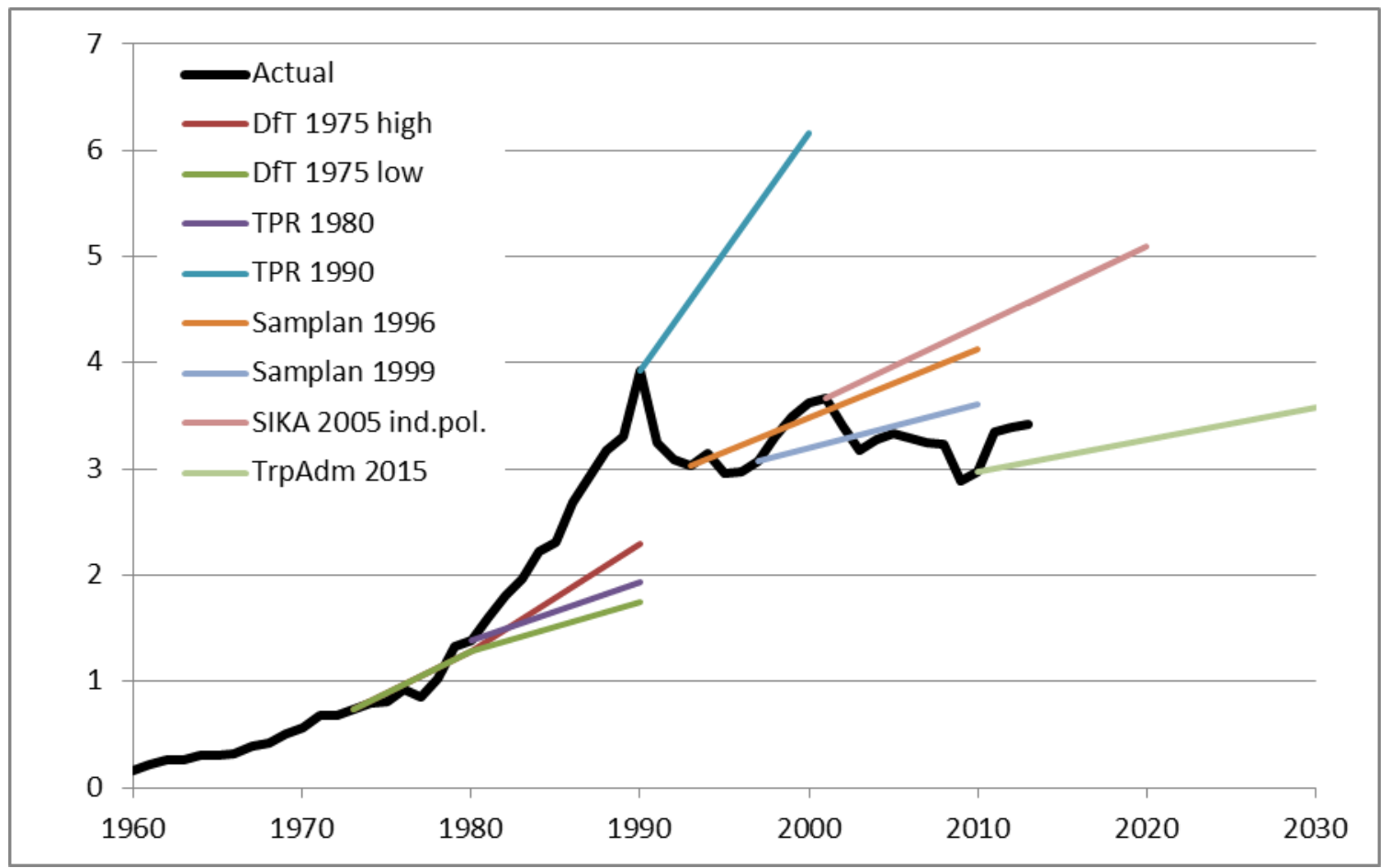

Figure 7. Total air passenger kilometers (billions): forecasts and outcomes.

The early forecasts for domestic air predicted an increase, but not as rapid as the actual development in the 1980s. TPR (1990) predicted that this rapid increase would continue - but in fact the forecast was published at the absolute peak for domestic air travel. Instead, domestic air travel declined rapidly during the early 1990s. On average, travel volumes have remained at around the same levels, increasing and decreasing with the business cycle, but with no apparent growth trend. Forecasts, however, have predicted more or less rapid increases in domestic air traffic. The reason for the overestimation in the 1990 forecast is clear: the forecast was built on assumptions about new airports and new domestic flight connections, but the deregulation of domestic air traffic in 1990 instead led to drastic price increases and decreased supply (the number of landings is still $37 \%$ lower than in 1990). Together with the economic downturn in the early 1990s, this led to a substantial decrease in demand for air travel.

Generally, less attention has been paid to air forecasts because they have rarely been used for infrastructure and policy planning. The airports are not publically funded, and the aviation authority makes their own forecasts.

\subsection{Summary and discussion}

In general, we find that there are substantial differences between forecasts of aggregate passenger kilometers per mode and actual outcomes.

- Since the early 1990s, forecasts for car traffic have generally predicted growth rates of around $1.5 \%$ per year on average, whereas actual growth rates have been around $0.8 \%$ per year. The latest forecasts, where actual outcomes are of course still unknown, also predict growth rates of around 1.5\% per year.

- Railway forecasts since the early 1990s have been fairly accurate on an aggregate level. The forecasts of the 1990s predicted substantial growth, which came to pass. In fact, the growth was even higher than predicted due to much faster growth in regional train travel than predicted. This growth seems to have been fueled to a large extent by a substantial and unpredicted expansion of the subsidized public transport 
supply. The forecasts of the 2000s have so far been fairly accurate on an aggregate level. However, interregional railway traffic has grown slower than predicted, whereas subsidized (mainly intraregional) public transport has grown faster than predicted.

- Forecasts of air travel demand have consistently overpredicted actual demand. An important reason seems to be the deregulation of domestic air traffic in the early 1990s. In subsequent forecasts, the changes in supply and pricing following this seem to have been neglected. It should be noted, however, that this has probably not been a serious problem in practice because these forecasts have not been used much in actual planning. In fact, it is evident in the forecast documentation that not much trust was placed in these forecasts even at the time they were made.

It is important to note that finding deviations between a forecast and an outcome does not necessarily mean that an original forecast was "wrong". In particular, decision makers might respond to a forecast by implementing policy measures intended precisely to counteract the forecast. For example, if car traffic is predicted to grow at a rate higher than what is compatible with political goals (e.g. for climate policy), then politicians might respond by increasing fuel taxes, which will then lead to a lower growth rate than originally forecast (if the fuel tax works as intended). Similarly, if, for example, railway traffic is predicted to lose market shares to air or car traffic, politicians or railway operators might respond by increasing supply or lowering railway fares to increase ridership. Often this is the purpose of making the forecast in the first place - to predict the development in a "do-nothing" alternative in order to understand what policy measures are needed. In such cases, forecasts should really not be interpreted as statements saying "this will happen", but rather, "this will happen if nothing is done".

On the other hand, forecasts are often also used as references for analyzing individual policies, especially infrastructure investments. In such cases, the analyst needs a reference forecast that actually represents a best estimate of the most likely outcome. It is thus useful to distinguish between two types of forecasts: "do-nothing" forecasts, where the intention is to generate policy responses, and "most likely outcome" forecasts, where the intention is to represent a most likely reference scenario to be used for things like investment appraisal. However, this distinction is often blurred in practice ${ }^{2}$. One of the reasons for this is that it is politically sensitive to explicitly point out what the most likely outcome is. For example, politicians might state a goal of limiting the growth of car traffic to some number, while at the same time ruling out most or all relevant policy measures such as higher fuel taxes or stimulating urbanization. In such a situation, establishing a "most likely outcome" forecast is both difficult and politically sensitive because it amounts to second-guessing politicians' actual intentions or future decision which might not coincide with (all of their) stated goals.

When discussing forecasting errors, it is useful to distinguish between different sources of errors.

1. Model deficiencies. Forecasting models might, of course, be fraught with errors and deficiencies in their underlying theories, estimation methodologies, model implementation, data used for the estimation and so on. An important type of error is that models might not take all relevant variables into account, which is probably more often due to data limitations than to negligence by the model developers. For example, it is often very difficult to get data about train fares in commercial traffic.

\footnotetext{
${ }^{2}$ In Sweden, forecasts have usually been produced assuming no future policy measures (such as changes in fuel taxes) except those already decided by the Government.
} 
2. Differences between cross-sectional and intertemporal relationships. Virtually all transport models that are able to generate detailed forecasts (on, say, network or origin-destination levels) are estimated based on cross-sectional data. Using such models to predict future reference forecasts thus rests on the tacit assumption that cross-sectional and intertemporal relationships are equal. (Note that this is much less of a problem when making policy forecasts, i.e. predicting the effect of a specific policy or investment.) For example, say that there is a cross-sectional relationship between income and travel behavior that persists even after controlling for variables such as education, age, car ownership, and so on. Using a model estimated on cross-sectional data to forecast future travel then tacitly assumes that the same relationship also holds intertemporally. In other words, if income grows such that tomorrow's poor have the same real income as today's average, the poor of tomorrow will make travel choices in the same way as today's average (all else being equal). Obviously, there are great risks for confounding and self-selection here. To what extent this is a problem in practice is unclear and there is not a lot of systematic research comparing cross-sectional and inter-temporal relationships.

3. Changes in preferences or behavior. Using models to predict the future also tacitly assumes stability in preferences and behavior in two senses. First, it is assumed that travel behavior will only change to the extent that underlying variables (travel times, travel costs, incomes, etc.) change. Second, it is assumed that such variables will affect travel behavior in the same way in the future as they have done up to the present. Obviously, both are strong assumptions. Note that it is mainly the second assumption that is crucial for policy forecasting, whereas both are essential for reference forecasting.

4. Assumption errors. For reference forecasting, it is necessary to make a large number of assumptions about future transport supply (travel times, costs, etc.) and general societal variables (income, population, age, household structures, etc.).

Several previous studies have concluded or hypothesized that assumption errors can explain a large share of forecasting errors (de Jong et al., 2007). In the next section, we try to adjust car traffic forecasts to account for assumption errors.

\section{ACCOUNTING FOR ERRORS IN INPUT ASSUMPTIONS}

Reference forecasts rest on assumptions about a large number of variables, including fuel price, population, GDP, and so on. Several of these variables also need to be broken down spatially on a very detailed level. When making reference forecasts for passenger transport, some variables are usually "exogenous", meaning that they are taken from external sources, whereas some variables are produced in conjunction with making the forecast - car ownership and detailed spatial breakdowns of socioeconomic data are perhaps the most common and important examples. Hence it is often not clear-cut (at least for an external observer) which variables can be regarded as "exogenous" to the forecasting process and which variables can be regarded as being part of the forecasting process.

Some studies have concluded, hypothesized, or implied that assumption errors can explain a large share of forecasting errors (Andersson et al., 2011; de Jong et al., 2007; Tegnér, 2001). In this section, we explore how most forecast errors can be explained by assumption errors. We focus on car traffic, mainly because there is hardly any 
documentation of railway or bus supply data used in the forecasts, which makes correcting for such supply assumptions impossible.

Ideally, the old forecasting models would have been re-run with correct input assumptions, but because these old models have become inoperable over time, we have had to resort to an indirect method. Using the current version of the national transport model Sampers, we calculated the aggregate elasticities of car traffic (passenger kilometers) with respect to the most important input variables, including income, fuel price, car ownership, and population. We then used these elasticities to adjust the original forecasts for assumption errors. Obviously, using the elasticities of the current transport model rather than the original models is not ideal. However, there is some evidence indicating that elasticities seem to have remained broadly constant over time and across models. In the next subsection (5.1), we compare cross-sectional elasticities from the current Sampers model to available elasticities from old models. More importantly, we compare these cross-sectional elasticities to elasticities estimated on time-series, thus exploring whether there are differences between cross-sectional and intertemporal elasticities.

Unfortunately, variable assumptions are not always documented, so all forecasts cannot be corrected, even for errors in the variables mentioned above. Moreover, there are several more variables that affect forecasts that are impossible to adjust for. For example, we cannot adjust for assumption errors regarding infrastructure supply such as road speeds, infrastructure investments, public transport services, etc. Thus, our results have to be seen as indicative rather than conclusive.

The above 'adjustment' method based on elasticities is only relevant for aggregate indicators of input errors, for which it has been possible to compute the current models' elasticities. For most variables, however, real input data are very disaggregate. Therefore, errors regarding the (geographical) distribution of input variables can also cause forecasts to deviate from what would have been forecasted based on correct assumptions. An example of a potential source of error of that kind is the distribution of population among different types of municipalities that reflects the pace and degree of urbanization. For one of the car traffic forecasts - for which a somewhat disaggregated representation of input was available - we have made an attempt to adjust for such differences. Instead of applying elasticities, we assumed in the analysis that the model's (semi)aggregate behavior can be approximated by the real variation in average car kilometers driven per person between municipalities as calculated from vehicle inspection data and population statistics.

Moreover, we have analyzed the error caused by the assumption about a fixed distribution of driving licenses between car owning and non-car owning households, respectively. This assumption, with the same parameter as estimated in 1992, has been hard-wired into all software implementations of Sampers. This is not an input error in a strict sense because the parameter is not in the input. Nevertheless, the effect of the deviation between the in-built parameter and its corresponding value in the population in the forecast year could be inferred from the model's elasticity with respect to the total number of driving licenses.

\subsection{Cross-sectional vs. time-series elasticities}

Cross-sectional elasticities in the current national transport model (Sampers) were calculated by increasing variables (one at a time) by $10 \%$ and calculating the resulting 
change in VKT. Denoting the change in VKT by $\Delta$, the corresponding elasticity $\varepsilon$ was then calculated as

$$
\varepsilon=\frac{\ln (1+\Delta)}{\ln (1+10 \%)}
$$

In order to compare cross-sectional and intertemporal elasticity, a simple time series model was estimated based on the years 1980-2013 by regressing the VKT on GDP/capita and fuel price (in real terms):

$$
\ln \left(V K T_{t}\right)=\alpha+\beta \ln \left(G D P_{t} / \operatorname{cap}_{t}\right)+\gamma \ln \left(\text { price }_{t}\right)+\varepsilon_{t}
$$

The estimated time series fit the data fairly well (Figure 8; R2 = 0.81). Complete estimation results and quality discussion can be found in Appendix 1. Unfortunately, GDP per capita and car ownership cannot both be included in the model because they are too highly correlated.

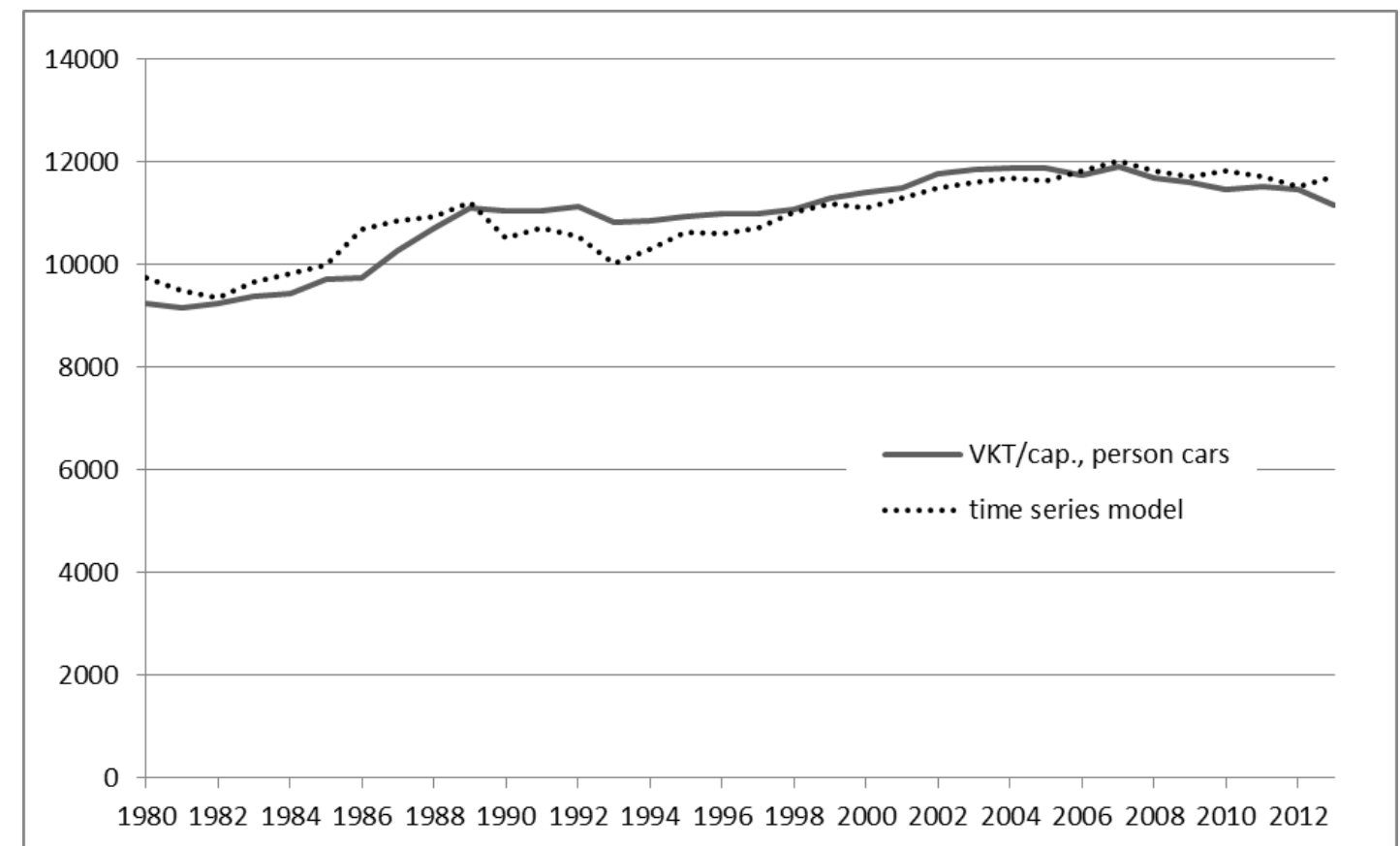

Figure 8. VKT 1980-2013, actual figures (solid) compared to the time series model (dotted).

Table 4 shows elasticities from the time series estimation and from the old crosssectional models where elasticities can be found in the documentation. First of all, the elasticities from the current version of the cross-sectional Sampers model are close to the elasticities from the time series model. This supports the crucial assumption for reference forecasting that cross-sectional and intertemporal elasticities are equal. The fuel price elasticity is actually exactly equal. Moreover, there is information about the fuel price elasticity for three earlier model versions, and these are also very close in two cases and reasonably similar in the third case. The Sampers income elasticity ${ }^{3}$ is 0.42 , while the GDP/capita elasticity from the time series model is slightly higher at 0.5.

\footnotetext{
${ }^{3}$ The Sampers model takes income into account in the following three ways: through a global variable that adjusts the cost sensitivity in the demand models, through the socioeconomic data tables for each zone (SAMS areas), and through the car ownership model.
} 


\begin{tabular}{|l|c|c|c|}
\hline & Fuel price & $\begin{array}{c}\text { Income } \\
\text { (GDP/capita) }\end{array}$ & $\begin{array}{c}\text { Car } \\
\text { ownership }\end{array}$ \\
\hline Time series & -0.22 & 0.5 & $\mathrm{n} / \mathrm{a}$ \\
\hline Sampers, current version & -0.22 & 0.42 & 0.40 \\
\hline Sampers, 2005 version & -0.21 & Unknown & Unknown \\
\hline VTI 1992 model & -0.13 & Unknown & Unknown \\
\hline TPR 1990 model & -0.28 & Unknown & Unknown \\
\hline
\end{tabular}

Table 4. Elasticities from times series estimation and cross-sectional models.

For our purposes, two important conclusions can be drawn:

- When adjusting the original forecasts, we have no choice but to use the current Sampers elasticities. However, there is some evidence that elasticities are fairly similar between cross-sectional models, so this seems to be a defensible assumption.

- Elasticities from cross-sectional and time-series models are remarkably close. This supports the non-trivial assumption that cross-sectional and intertemporal elasticities are equal, which is a necessary assumption in order to use models based on cross-sectional data to produce reference forecasts.

\subsection{Errors in input assumptions}

Arguably, the most important input variables when producing reference transport forecasts, at least for aggregate car traffic, are average income (usually taken to be equal to GDP/capita), population, fuel price, car ownership, and vehicle fuel economy. Most transport forecasts make explicit assumptions about the future levels of these variables, perhaps with the exception of vehicle fuel economy, which is often implicitly taken to be constant. Table 5 and Figure 9 show the assumed and actual change during the forecast period for each input variable. An empty cell means that the value cannot be found in the forecast documentation. In those cases, we obviously cannot adjust the original forecast, and this is the primary reason that our results should only be viewed as indicative and not as conclusive.

\begin{tabular}{|c|c|c|c|c|c|c|c|c|c|c|c|c|}
\hline & & & \multicolumn{2}{|c|}{$\begin{array}{l}\text { Fuel price } \\
\text { SEK/litre } \\
\end{array}$} & \multicolumn{2}{|c|}{$\begin{array}{c}\text { Fuel economy } \\
\text { Litre/km }\end{array}$} & \multicolumn{2}{|c|}{$\begin{array}{c}\text { Car ownership } \\
\text { Cars/person }\end{array}$} & \multicolumn{2}{|c|}{$\begin{array}{c}\text { Growth } \\
\text { GDP/capita } \\
\end{array}$} & \multicolumn{2}{|c|}{$\begin{array}{c}\begin{array}{c}\text { Population } \\
\text { growth }\end{array} \\
\end{array}$} \\
\hline TPR 1990 & 1990 & 2000 & $8 \%$ & $21 \%$ & $-8 \%$ & $-4 \%$ & $23 \%$ & $8 \%$ & $21 \%$ & $20 \%$ & $3 \%$ & $4 \%$ \\
\hline TPR 1990 & 1990 & 2010 & $18 \%$ & $41 \%$ & $-13 \%$ & $-10 \%$ & & & $46 \%$ & $39 \%$ & & \\
\hline VTI 1992 & 1991 & 2005 & & & & & $14 \%$ & $10 \%$ & $34 \%$ & $36 \%$ & & \\
\hline VTI 1992 & 1991 & $\begin{array}{c}2013 \\
(2020) \\
\end{array}$ & & & & & & & $58 \%$ & $44 \%$ & & \\
\hline $\begin{array}{l}\text { Samplan } \\
1996 \\
\end{array}$ & 1993 & 2010 & $0 \%$ & $35 \%$ & & & $24 \%$ & $15 \%$ & $38 \%$ & $48 \%$ & & \\
\hline $\begin{array}{l}\text { Samplan } \\
1999 \\
\end{array}$ & 1997 & 2010 & $0 \%$ & $33 \%$ & $-14 \%$ & $-9 \%$ & $12 \%$ & $11 \%$ & $28 \%$ & $33 \%$ & $3 \%$ & $6 \%$ \\
\hline
\end{tabular}


Table5. Input variables: assumed values (used in forecasts) and actual outcomes. Empty cells: values cannot be found in forecast documentation.

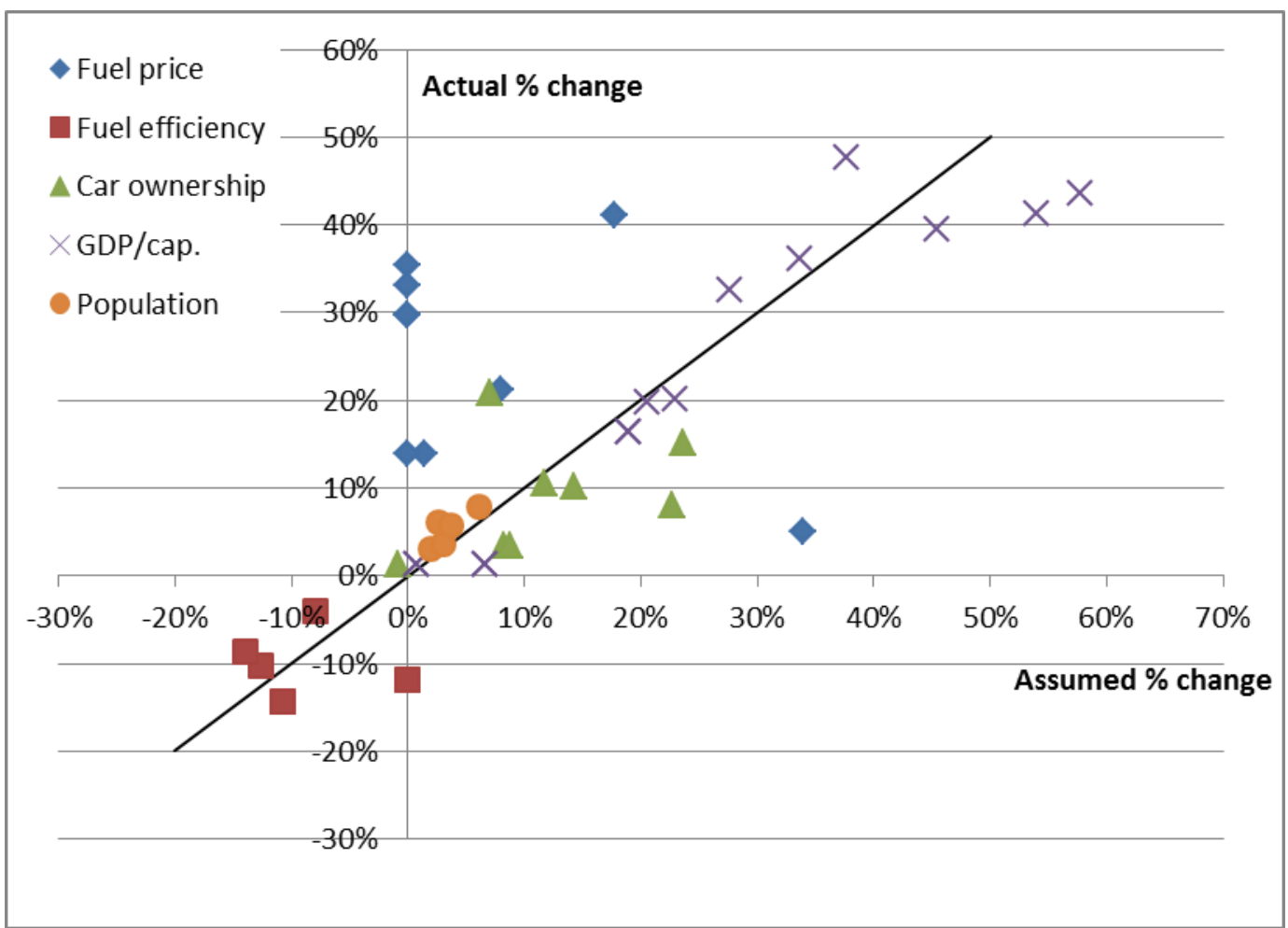

Figure 9. Input variables scattergram: assumed (x-axis) and actual (y-axis) percentage change over the respective forecast periods.

It is apparent that outcomes often differ substantially from assumptions. Fuel price has in most cases increased faster than assumed, while fuel economy has in most cases increased slower than assumed. Fuel costs in Sweden increased by $72 \%$ in real prices from 1992 to 2013, which was not captured in the forecasts. This is a systematic error because all forecasts since 1990 have missed this. Increased taxes account for $42 \%$ of the fuel price increase, so one could argue that failure to correctly incorporate future tax increases in the input should not be regarded as an input error because forecasts are not usually intended to reflect any policy changes except those that have already been decided upon. However, half of the increase in tax earnings is VAT, which follows the increase in crude oil prices and require no new policy decisions. Therefore, the assumption of "only decided policy measures" has not had that large of an impact on the systematic under-prediction of future fuel prices. (Whether the principle to include only already decided policy changes is reasonable or not depends on the purpose of the reference forecast; see the discussion in section 4.55.) Compared to fuel prices, total driving costs are even more systematically underestimated. This is due to overoptimistic assumptions about increased fuel economy. Until the SIKA 2005 forecast, the assumed development of fuel economy was based on time series-analysis, while forecasts from 2009 uses predictions from the Swedish car fleet model.

Assumptions about growth in GDP and car ownership (where GDP is an input) have been slightly more accurate, but with some tendency for overestimation. Because the number of data points is small, these tendencies should be treated with care, especially given the unusually large fuel price increase and slow economic growth of the last decade. 
A potential source of error that cannot be represented by one-dimensional elasticities is the assumption in the input data about how population growth will be distributed among different types of municipalities. In Sweden, as in many other countries, there has been a rapid urbanization with a successively larger proportion of Swedes living in Stockholm and other larger cities. Because inhabitants in large cities drive less, a misrepresentation of the populations' geographical distribution in the future scenario would be expected to be reflected by a corresponding error in the aggregate forecast for kilometers driven by car. Unfortunately, it is only for the forecast made in 2005 that we have had access to detailed demographic input. The data show that the pace of urbanization was indeed under-predicted in the input. For instance, it was assumed that out of the total population growth in Sweden between the base (2001) and the forecast year (2025), 8\% growth would occur in Stockholm municipality and 22\% growth would occur in Stockholm County. Statistics show that the corresponding real figures for 2001-2014 are much higher at $19 \%$ and $32 \%$ respectively. If the correct population distribution among municipalities for 2014 would have been represented in the input, it would have led to a slightly lower prediction of total car kilometers driven in Sweden $(-0.4 \%)$. This is under the assumption that for each municipality the predicted number of kilometers driven per capita would be proportional to real observations.

License holding is obviously an important determinant of car driving. In the forecasts we studied, standard practice seems to have been to assume that the share of license holding is constant. This coincides with reality, the share of license holders in the population above the legal driving age of 18 years has remained constant at 78\%. However, this obscures an important change over time - the license share for people older than 70 years has increased steadily, while the license share for people younger than 40 years has decreased steadily. This has caused the license share in households with access to a car to decrease, which has had a systematic effect on road mileage. In a way, this is an "input error" analogous to the other ones we study (fuel prices etc.), but it can also be viewed as a model-specification error. In fact, there is no variable reflecting "license share in car-owning households" in the model implementation - only the variables "license share in the population" and "share of households with access to a car". For the limited number of forecasts for which it was possible, we have calculated how getting this variable correct would have affected forecasts (Table 6). In most cases, it turns out that this is a significant contribution to forecasting errors, for example it explains $2 / 3$ of the error in the Samplan 1999-forecast.

Table 6. Changes in forecasts when the correct license share per car-owning household is used.

\begin{tabular}{|l|c|c|c|c|}
\hline Forecast & $\begin{array}{c}\text { Forecast traffic } \\
\text { growth }\end{array}$ & $\begin{array}{c}\text { Actual traffic } \\
\text { growth }\end{array}$ & $\begin{array}{c}\text { Change in forecast } \\
\text { Difference between } \\
\text { forecasted and actual } \\
\text { with correct license } \\
\text { share per car-owning } \\
\text { household }\end{array}$ \\
\hline $\begin{array}{l}\text { TPR 1990 } \\
(1990-2000)\end{array}$ & $20 \%$ & $8 \%$ & $12 \%$ & $-4.4 \%$ \\
\hline $\begin{array}{l}\text { Samplan 1996 } \\
(1993-2010)\end{array}$ & $30 \%$ & $20 \%$ & $10 \%$ & $-3.6 \%$ \\
\hline $\begin{array}{l}\text { Samplan 1999 } \\
(1997-2010)\end{array}$ & $20 \%$ & $16 \%$ & $4 \%$ & $-2.7 \%$ \\
\hline $\begin{array}{l}\text { SIKA 2005 } \\
(2001-2013)\end{array}$ & $18 \%$ & $11 \%$ & $7 \%$ & $-2.4 \%$ \\
\hline $\begin{array}{l}\text { Trp Adm 2009 } \\
(2006-2013)\end{array}$ & $31 \%$ & $19 \%$ & $12 \%$ & $-1.3 \%$ \\
\hline
\end{tabular}




\subsection{Comparing adjusted forecasts with outcomes}

Table 77 shows what happens with forecasts when they are adjusted for assumption errors, i.e. when they are corrected (to the greatest extent possible) for input variables that turned out differently than assumed at the time of the forecast. The subsequent tables do not correct for urbanization or share of licenses in car-owning households because this cannot be done using aggregate data. The first column of figures shows the 10-year linear trend proceeding the year the forecast was made. Arguably, the null hypothesis of a forecast would be to assume that transport would continue along the same path. Accuracy of forecasts is thus best judged against whether they perform better than a simple trendline. The second column shows the forecast of car traffic growth up to the forecast year (base years and forecast years are shown in parentheses).

The next four columns show how the forecasts change as they are adjusted for actual population growth, fuel prices, fuel economy, car ownership, and GDP per capita. Changes are made cumulatively, i.e. each column builds on the preceding one and adjusts one more variable. The penultimate column thus shows the forecasts adjusted for all five variables we have access to. The final column shows actual outcomes.

\begin{tabular}{|l|c|c|c|c|c|c|c|c|}
\hline & Trend & Forecast & $\begin{array}{l}\text { Adj. for } \\
\text { pop. } \\
\text { growth }\end{array}$ & $\begin{array}{l}\text { \& adj. for } \\
\text { fuel price }\end{array}$ & $\begin{array}{l}\& \text { adj. for } \\
\text { fuel } \\
\text { economy }\end{array}$ & $\begin{array}{l}\text { \& adj. for } \\
\text { car } \\
\text { ownership }\end{array}$ & $\begin{array}{l}\text { \& adj. } \\
\text { for GDP }\end{array}$ & Actual \\
\hline TPR 1980 (1980-1990) & $46 \%$ & $5 \%$ & $6 \%$ & $11 \%$ & $11 \%$ & $17 \%$ & $16 \%$ & $25 \%$ \\
\hline TPR 1990 (1990-2000) & $25 \%$ & $20 \%$ & $20 \%$ & $16 \%$ & $15 \%$ & $9 \%$ & $9 \%$ & $8 \%$ \\
\hline TPR 1990 (1990-2010) & $50 \%$ & $31 \%$ & $31 \%$ & $26 \%$ & $25 \%$ & $18 \%$ & $16 \%$ & $19 \%$ \\
\hline VTI 1992 (1991-2005) & $38 \%$ & $26 \%$ & $26 \%$ & $17 \%$ & $18 \%$ & $16 \%$ & $17 \%$ & $15 \%$ \\
\hline VTI 1992 (1991-2013) & $59 \%$ & $41 \%$ & $41 \%$ & $26 \%$ & $32 \%$ & $30 \%$ & $24 \%$ & $20 \%$ \\
\hline Samplan 1996 (1993-2010) & $38 \%$ & $30 \%$ & $30 \%$ & $21 \%$ & $24 \%$ & $20 \%$ & $24 \%$ & $20 \%$ \\
\hline Samplan 1999 (1997-2010) & $19 \%$ & $20 \%$ & $24 \%$ & $12 \%$ & $11 \%$ & $10 \%$ & $12 \%$ & $16 \%$ \\
\hline SIKA 2005 LU (2001-2013) & $10 \%$ & $18 \%$ & $20 \%$ & $11 \%$ & $12 \%$ & $10 \%$ & $9 \%$ & $11 \%$ \\
\hline Trp Adm 2009 (2006-2013) & $10 \%$ & $6 \%$ & $8 \%$ & $3 \%$ & $6 \%$ & $7 \%$ & $5 \%$ & $3 \%$ \\
\hline Root Mean Square Error & 0.64 & 0.38 & 0.39 & 0.18 & 0.21 & 0.14 & 0.12 & \\
\hline
\end{tabular}

Table 7. Car traffic growth: 10-year trend at time of forecast, forecast, forecast adjusted for assumption errors (cumulative), and actual outcome.

The largest source of error is the fuel price assumption, which has caused an average absolute error of 6 percentage points averaged over the forecasts in Table 7. The fuel price has been systematically underestimated in all forecasts since 1990. Car ownership assumptions have also been an important source of error with an average absolute error of 3 percentage points, especially in earlier forecasts, but the errors have not been systematic as there were underestimations in the 1980 forecast and overestimations in the 1996 and 1999 forecasts. The assumption errors for car ownership in the 2005 and 2009 forecasts are small. In forecasts since 2005, GDP has been the largest source of error due to the sluggish economic growth since 2008. The average absolute error over all forecasts is 3 percentage points, but since 2005 the GDP assumption errors have caused a systematic overestimation by 5 percentage points on average.

A natural way to assess the overall accuracies of forecasts is to compare the root mean square errors (RMSEs) of the trends, original forecasts, and adjusted forecasts to the actual outcomes. These are shown in the last row of Table 10. The original forecasts perform better on average than just simple trends with RMSE of 0.38 and 0.64 , respectively. However, when assumption errors are adjusted for, the RMSE improves 
substantially to 0.12 . It is primarily correcting the fuel price and GDP that improves accuracy.

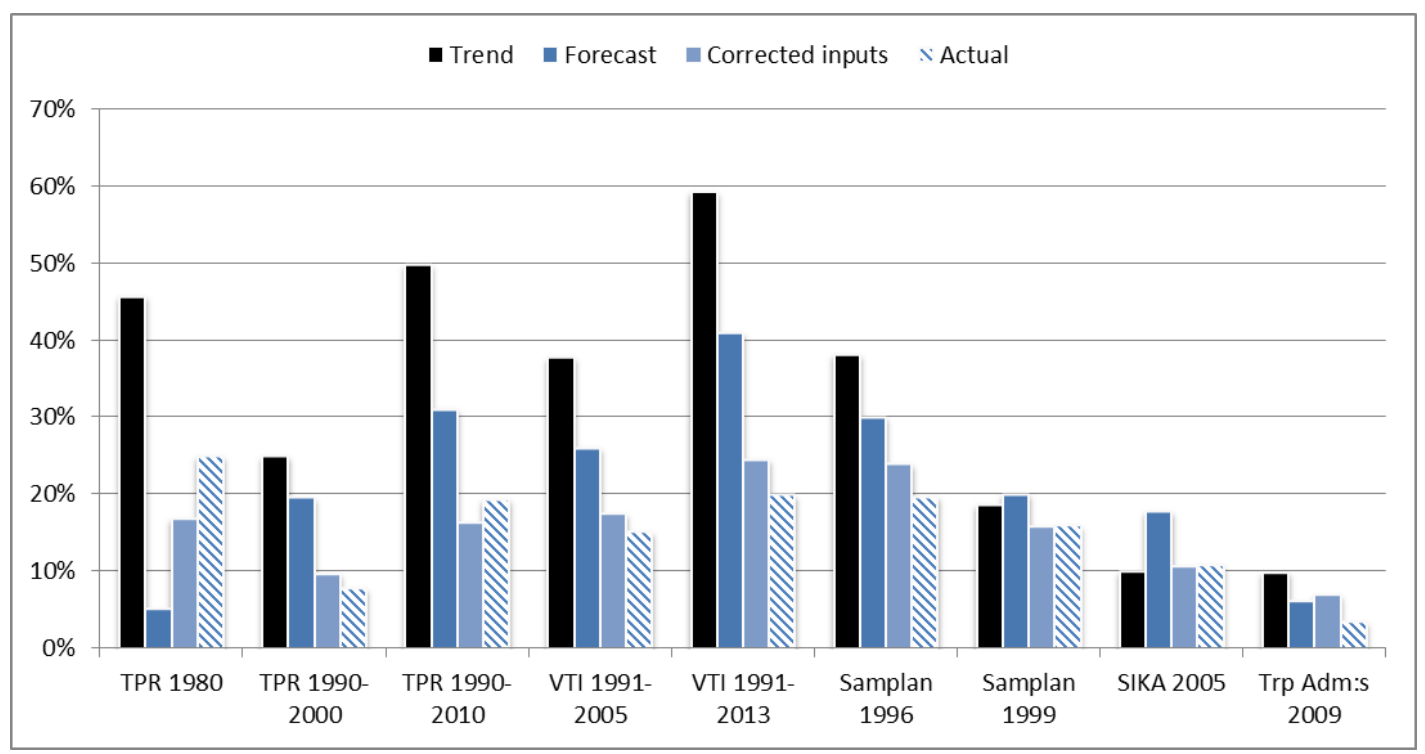

Figure 10. Trends, original forecasts, forecasts adjusted for assumption errors, and actual outcomes.

To provide a better overview, the results in Table 7 are summarized in Figure 100. The diagram clearly shows that the original forecasts are not simply trendlines. In almost all cases, even the original forecasts are closer to actual outcomes than simple trends would have been. It is also clear that once the input variables are adjusted, the forecasts come much closer to the actual outcomes. There are still some unexplained differences, but in almost all cases the remaining errors are fairly small at less than 5 percentage points. The exceptions are the TPR 1990-2010 forecast, with an absolute error of 8 percentage points, and the VTI 1992-2013 (2020) forecast with an absolute error of 13 percentage points. It is probably not incidental that these are the forecasts with the longest time horizons.

Again, it should be stressed that it has not been possible to adjust all assumption errors, not even the most important ones in all cases, because input assumptions are often not documented in the original reports. Thus, it is possible that the adjusted forecasts would have been even closer to outcomes had all assumptions been corrected.

Figure 111 and Figure 122 provide two more illustrations comparing adjusted forecasts with actual outcomes. Figure 111 is the adjusted analogue to Figure 4 illustrating forecasted trends compared to actual developments. Again, it is evident that several forecasts have overpredicted the growth of car traffic, even after adjusting the input assumption to the extent that is possible, but it is also evident that several of the adjusted forecasts have predicted actual outcome very well. Figure 112 is the adjusted analogue to Figure 5 comparing the adjusted predictions with actual traffic growth per year. 


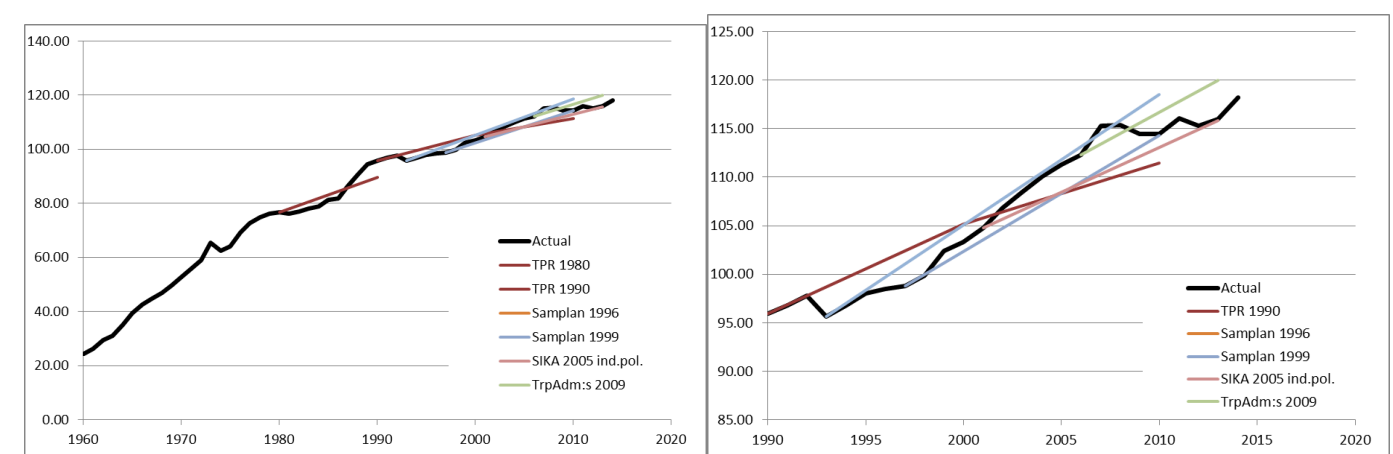

Figure 11. Adjusted forecasts and actual outcomes for car traffic (the right diagram starts at 1990 for clarity).

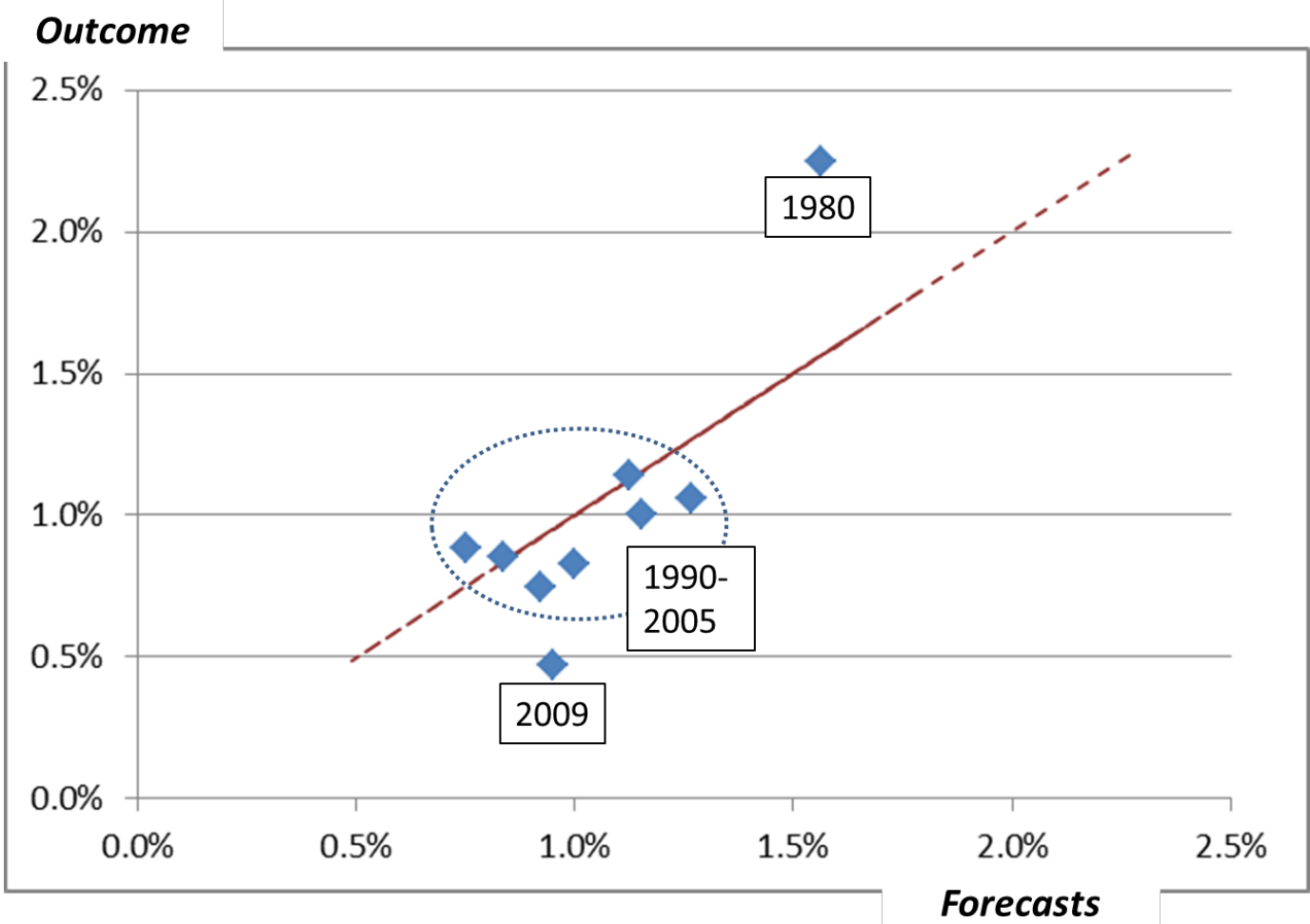

Figure 12. Traffic growth per year: adjusted forecasts (x-axis) and outcomes (y-axis).

In conclusion, a very large share of total forecast errors can be explained by input variables being different in reality from what was assumed in the forecasts. This, together with the fact that even the original forecasts perform much better than simple trendlines (and the adjusted forecasts much more so), is a testimony to the explanatory power of the models. This result, and the consistency between elasticities from time series and cross-sectional models, indicates that the potential problems of using crosssectional models for forecasting intertemporal changes are in fact limited.

From a model development point of view, this is to a large extent a comforting conclusion. But on its own, it does not solve the problem that the original reference forecasts deviate substantially from actual outcomes. How serious this problem is depends on the purpose of using the model. For policy analysis, when the purpose is to study how a change in a particular variable affects, say, car traffic, this is less of a problem. But in cases where absolute traffic levels are important - say, for predicting future toll revenues or capacity needs - then differences between reference forecasts and outcomes still constitute a problem. Concluding that errors are largely caused by wrong assumptions about input variables are interesting and potentially useful - but just 
knowing this does not solve the problem. To get further, some conclusions need to be made about the input errors we encountered.

- Based on our investigation it is hard to give recommendations on how to make better GDP, car ownership, and fuel price forecasts. An interesting aspect, though, is that the rise in oil prices have stopped, and even started to decline (which if it continues means that oil prices will not contribute to overpredictions).

- Population forecasts have been too low, but knowing that immigration has usually been underestimated might improve future forecasts. Similar reasoning holds for fuel economy: knowing that most forecasts have been too optimistic is useful information.

- The most concrete advice we can give future forecasters concerns driving licenses in car-owning households. A simple calculation of the effect of younger people not getting driving licenses and more elderly having licenses improves the forecasts significantly.

Because the future values of input variables will always be hard to predict, sensitivity analysis will always be valuable. An interesting observation is that none of the sensitivity analyses during the last decades have been as low as the actual outcome for car traffic. Although the purpose of the sensitivity analyses has not been to capture minimum and maximum outcome but to describe the effect of different policies or in some cases changes in certain inputs, this is cause for some concern. The main constraint, in our opinion, is not data power, but imagination. Of course, full-scale model runs for a large number of input variable combinations is infeasible in practice, but illustrating uncertainties using aggregate elasticities is both feasible and sufficiently illustrative of the scale of uncertainty in various respects.

\section{CONCLUSIONS}

Comparing national reference forecasts with actual outcomes over several decades shows that there are substantial differences between forecasts of aggregate passenger kilometers per mode and actual outcomes. Since the early 1990s, forecasts for car traffic have generally predicted growth rates of around $1.5 \%$ per year on average, whereas actual growth rates have been around $0.8 \%$ per year. Railway forecasts since the early 1990s have been fairly accurate on an aggregate level, but this is largely because overpredictions of interregional, long-distance railway travel has been canceled out by underpredictions of subsidized, intra-regional trains (fueled by unanticipated supply increases). Forecasts of air travel demand have consistently overpredicted actual demand, largely because deregulation led to unanticipated decreases in supply.

Still, even the original forecasts are closer to actual outcomes than simple trendlines would have been. Moreover, a very large share of forecast errors can be explained by input variables turning out differently than what was assumed in the forecasts. This is a testimony of the explanatory strength of the models. It also indicates that the potential problems of using cross-sectional models for forecasting intertemporal changes seem to be limited. Further support for this is given by the consistency between the elasticities from the cross-sectional models and those from our time-series model. Although the models beat trendlines and it should be "allowed" to make forecasts that break the current trend, we think that such trend breaks should be commented upon in the forecast reports.

Reference forecasts form an important baseline for analyzing individual policies, in particular designing and evaluating infrastructure investments. Such analyses ideally 
need a best estimate of the most likely future situation. The conclusion that most of the observed forecasting errors seem to be explained by assumption errors is comforting in the sense that models are broadly trustworthy - but it does not in itself make the choice of input variables easier. We are able to draw some conclusions on how to set some of the input variables in a better way, but extensive and systematic sensitivity analyses are still useful and necessary. Neither of these solves the problem that some central input variables are politically sensitive because politicians might state certain goals while simultaneously ruling out most or all policy measures needed to reach such goals. Establishing input variables by second-guessing politicians' actual intentions and future decisions is, of course, politically sensitive - in particular if these are not consistent with stated goals.

\section{ACKNOWLEDGEMENTS}

We thank the Swedish Road and Rail Administration (Trafikverket) for funding this paper.

\section{REFERENCES}

Andersson, M., Pettersson, K., Almström, P., Engelson, L., Van Amelsfort, D., Lundin, M., Hagson, A. (2011). Inducerad trafikefterfrågan i dagens modeller för planering av och beslut om infrastruktur (Trafikverket Rapport 2011:052).

Bain, R. (2009). Error and optimism bias in toll road traffic forecasts. Transportation, 36, 469-482.

Beser, M., \& Algers, S. (2002). SAMPERS - The New Swedish National Travel Demand Forecasting Tool. In: Lundqvist, L., Mattsson, L.-G. (Eds.), National transport models: recent developments and prospects. Springer.

Button, K. J., Doh, S., Hardy, M. H., Yuan, J., \& Zhou, X. (2010). The accuracy of transit system ridership forecasts and capital cost estimates. International Journal of Transport Economics / Rivista internazionale di economia dei trasporti, 37(2), $155-168$.

de Jong, G., Daly, A., Pieters, M., Miller, S., Plasmeijer, R., \& Hofman, F. (2007). Uncertainty in traffic forecasts: literature review and new results for The Netherlands. Transportation, 34(4), 375-395. 
Edwards, H., Nilsson, G., Thulin, H., \& Vorwerk, P. (1999). Trafikarbetet uttryckt $i$ fordonskilometer på väg i Sverige 1950-1997 (VTI Rapport No. 439).

Eliasson, J., \& Fosgerau, M. (2013). Cost overruns and benefit shortfalls - deception or selection? Transportation Research B, 57, 105-113.

Flyvbjerg, B. (2009). Survival of the unfittest: why the worst infrastructure gets builtand what we can do about it. Oxford Review of Economic Policy, 25(3), 344-367.

Flyvbjerg, B., Holm, M. S., \& Buhl, S. (2002). Underestimating Costs in Public Works Projects: Error or Lie? Journal of the American Planning Association, 68(3), 279295.

Flyvbjerg, B., Skamris Holm, M. K., \& Buhl, S. L. (2005). How (In)accurate Are Demand Forecasts in Public Works Projects?: The Case of Transportation. Journal of the American Planning Association, 71(2), 131-146.

Fouracre, P. R., Allport, R. J., \& Thomson, J. M. (1990). The performance and impact of rail mass transit in developing countries. Publication of: Transport and Road Research Laboratory, (RR 2).

Gunn, H., Miller, S., \& Burge, Peter. (2006). The External Validation of the NTM - Final Report. Presented at the European Transport Conference.

Kjerkreit, A., \& Odeck, J. (2009). The accuracy of ex-ante benefit cost analysis-a post opening evaluation in the case of Norwegian road projects. Presented at the International Transport Economics Conference, University of Minnesota.

Kommunikationsdepartementet. (1975). Transporter i Sverige [Transportation in Sweden] (Ds K No. 1975:4).

Ljungberg, C. (2014). Christer Ljungbergs Blogg | Diskussionen om trafikprognoserna ökar som tågtrafiken. www.christerljungberg.se

Nicolaisen, M. S. (2012). Forecasts: Fact or Fiction?: Uncertainty and Inaccuracy in Transport Project Evaluation (PhD Thesis). Aalborg University. 
Nicolaisen, M. S., \& Driscoll, P. A. (2014). Ex-Post Evaluations of Demand Forecast Accuracy: A Literature Review. Transport Reviews, 34(4), 540-557.

Odeck, J. (2013). How accurate are national road traffic growth-rate forecasts?-The case of Norway. Transport Policy, 27, 102-111.

Osland, O., \& Strand, A. (2010). The Politics and Institutions of Project Approval - a Critical-Constructive Comment on the Theory of Strategic Misrepresentation. European Journal of Transport and Infrastructure Research, 10(1).

Parthasarathi, P., \& Levinson, D. (2010). Post-construction evaluation of traffic forecast accuracy. Transport Policy, 17(6), 428-443.

Pickrell, D. H. (1992). A Desire Named Streetcar Fantasy and Fact in Rail Transit Planning. Journal of the American Planning Association, 58(2), 158-176.

SIKA. (2004). Transportarbetets utveckling. SIKA report No. 2004:7.

SIKA. (2005). Transportprognoser sedan 1975 [Transport forecasts since 1975]. SIKA report No. 2005:4.

Swedish Road and Transport Research Institute (VTI). (1992). Framtida transporter $i$ Sverige [Future transport in Sweden] (VTI Notat No. T117).

Tegnér, G. (2001). Ostkustbanan - modell och verklighet. [The Ostkustbanan railroad forecast and reality.]. Transek report (No. 2001-04-30). Transek AB.

Transportrådet. (1980). Transportsektorn. Redovisning av aktuell situation och prognos fram till år 1990 [The Transport sector. Presentation of the current situation and forecasts until 1990] (TPR No. 1980:3).

Transportrådet. (1991). Transportrådets modellsystem för persontrafik [Swedish transport councils' model system for passenger transport] (TPR No. 1991:3).

Welde, M. \& Odeck, J., (2011). Do Planners Get it Right? The Accuracy of Travel Demand Forecasting in Norway. European Journal of Transport and Infrastructure Research, 11(1), 80-95. 
Widlert, S., Swahn, H., Östlund, B., \& Algers, S. (1995). Co-ordinated infrastructure planning in Sweden. Presented at the 7th WCTR, Sydney.

\section{APPENDIX 1: TIME SERIES MODEL - ESTIMATION AND QUALITY}

In this appendix we describe our time series model from chapter 5.1 in more detail and discuss its pros and cons. The appendix is meant for the technically interested reader, it is not necessary for understanding the analysis in chapter 5 . Table 8 below shows the estimation results.

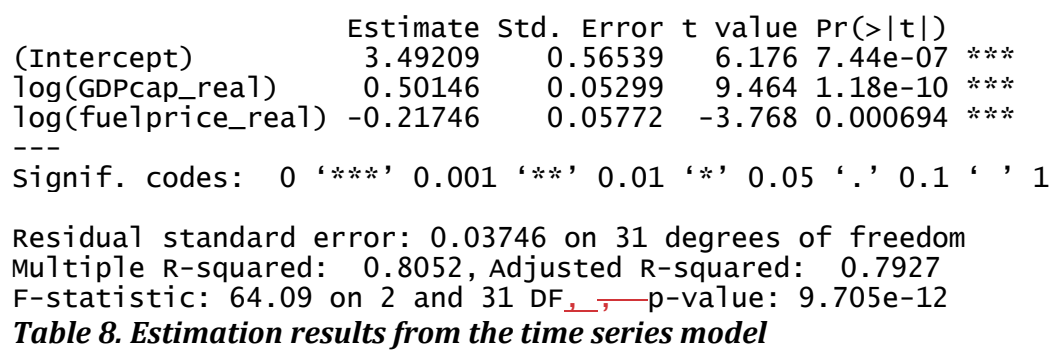

According to the Dickey-Fuller test, a unit root cannot be rejected even at the $10 \%$ level for road mileage $(1.15<3.18)$, but can be rejected when tested on the differentiated series. We draw the conclusion that road mileage is I(1). Disposable income per capita and fuel price are also I(1). A Durbin-Watson test gives 0.32, i.e. significant autocorrelation. Autocorrelation could mean that the OLS does not give the BLUE estimate (which we can live with), but it might also indicate missing variables (which might be a big problem). We have three arguments to still believe in our conclusion that the fuel price elasticity is low in the 2005 forecast and very low in the 1992 forecast:

i) A Johansen test for co-integration is significant at the 5\% level (31.53 > 29.68), which indicates that the correlation is not spurious and that we most likely do not have missing variables.

ii) Running the regression with differentiated values gives almost the same fuel elasticity $(0.26)$ with no autocorrelation (although $\mathrm{R}^{2}$ decreases from 0.67 to 0.14 ).

iii) The literature usually gives higher estimates of the long-term elasticity. Goodwin et al (2004) says (from a 10\% increase) "Volume of traffic will fall by roundly $1 \%$ within about a year, building up to a reduction of about $3 \%$ in the longer run (about 5 years or so)." Graham and Glaister (2004) concluded that the short-term elasticity is -0.15 and the long-term elasticity is -0.31 , quoting from (Graham and Glaister, 2002). Hughes et al (2008) argued that the elasticity has gone up over time, indicating that models used for forecasts two or three decades into the future might underestimate the elasticity. 